\title{
EL CONTRATO DE DEPÓSITO DE VALORES DE OFERTA PÚBLICA CON UNA EMPRESA DE CUSTODIA DE TALES*
}

\section{THE CONTRACT DEPOSIT PUBLICLY OFFERED SECURITIES WITH A COMPANY SUCH CUSTODY}

\author{
Alejandro Guzmán Brito* \\ José Luis Guerrero Becar ${ }^{* * *}$
}

\section{RESUMEN}

El artículo examina el régimen derivado de la ley $\mathrm{N}^{\circ} 18.876$, de 1989 , acerca del depósito de valores de oferta pública en las empresas de custodia de tales, que ella misma estableció y los problemas dogmáticos suscitados por ese régimen legal.

Palabras clave: Valores de oferta pública, ley $\mathrm{N}^{\circ} 18.876$, depósito de valores, empresas de depósito de valores.

\section{AbSTRACT}

The article examines the regime derivated of the Statute No. 18,876, of 1989 , about the values depository of public offer in companies of custody, which she self established and the dogmatic problems issued by this legal regime.

* Este trabajo fue compuesto como parte del proyecto de investigación patrocinado por el Fondo de Investigación Científica y Tecnológica, con el título de: "Los valores ante su depósito y eventual desmaterialización en el derecho chileno".

${ }_{* *}^{*}$ Doctor en Derecho. Profesor titular en la Facultad de Derecho de la Pontificia Universidad Católica de Valparaiso. Dirección postal: Avenida Brasil 2950, Valparaíso, Chile. Correo electrónico: aguzman@ucv.cl

*** Magister en Derecho. Profesor adjunto en la Facultad de Derecho de la Pontificia Universidad Católica de Valparaiso. Dirección postal: Avenida Brasil 2950, Valparaíso, Chile. Correo electrónico: jose.guerrero@ucv.cl

Artículo recibido el 22 de octubre de 2015 y aceptado para su publicación el 13 de enero de 2016. 
Key words: Values of public offer, Statute No 18.876, Values depository, Companies of values depository.

\section{INTRODUCCIÓN: EL DEPÓSITO ORDINARIO DE VALORES TITULADOS}

La ley $\mathrm{N}^{\circ} 18.876$ (DO. de 21 de diciembre de 1989) regula un especial contrato de depósito de valores, sean al portador, a la orden o nominativos, que se aparta en varios puntos del contrato ordinario de depósito descrito en el título $32^{\circ}$ del libro IV del $C C$ (arts. 2211 a 2214 ) y especialmente en el 11 de ese título (arts. 2215-2235).

Por Derecho Civil común el depósito recae sobre corporales muebles (artí. 2215 del $C C$ ); y nada se dice ahí acerca de un depósito de títulosvalor (o, si se quiere, de títulos-valor o, en la antigua terminología, de títulos de crédito). El Derecho Comercial común, en cambio, conoce un depósito de documentos de crédito ${ }^{1}$. El Derecho Mercantil especial también conoce un depósito de valores, como se ve en el art. $69 \mathrm{~N}^{\circ} 14$ del decreto con fuerza de ley $\mathrm{N}^{\circ} 3$ de 1997: Ley general de bancos $(D O$. de 19 de diciembre de 1997), que dice:

"Los bancos podrán efectuar las siguientes operaciones: [...]. 14. Recibir valores y efectos en custodia en las condiciones que el mismo banco fije y dar en arrendamiento cajas de seguridad para el depósito de valores y efectos";

lo cual no ha sido alterado por la ley $\mathrm{N}^{\circ} 18.876^{2}$.

Los casos especiales presentados muestran que un depósito de valores titulados no contiene nada contrario a las leyes o a los dogmas. Solo deben

${ }^{1}$ Art. 811 del CCom.: "Consistiendo el depósito en documentos de crédito que devenguen intereses, el depositario está obligado a cortarlos y a practicar todas las diligencias necesarias para conservar los derechos del depositante". No es requisito de este depósito que se devenguen intereses. La disposición regula el caso positivo; pero no impide el caso negativo. En síntesis, se pueden depositar documentos de crédito aunque no devenguen intereses.

2 Art. 47: "Lo dispuesto en la presente ley no alterará la facultad concedida a los bancos y sociedades financieras para recibir valores en custodia, de acuerdo con el artículo $69 \mathrm{~N}^{\circ} 14$ de la Ley general de bancos”. Sobre este depósito hay una antigua memoria de licenciatura de Jaime Castro Boissier (1959). Debe advertirse que existen entidades distintas a los bancos que giran con el contrato de depósito de valores. De hecho, el Banco Central puede actuar como depositario de los valores pertenecientes a las Administradoras de Fondos de Pensión (art. 44 del decreto-ley $\mathrm{N}^{\circ} 3.500$ ). El título $13^{\circ}$ del citado decreto-ley está destinado a regular la custodia de los títulos y valores de los fondos de pensiones. 
cumplirse dos exigencias. Una es que el valor del cual se trate conste en un "título", vale decir, en un soporte físico o material (como lo pide el art. 811 del CCom., al utilizar la expresión 'documento'), consistente en láminas de material generalmente celulósico (papel, cartulina, cartón, etcétera), y de manera excepcional de plástico. Esta constancia en un título imprime la calidad de corporal mueble (como lo pide el art. 2215 del $C C$ ) al valor que lo porta, y eso es suficiente para configurar un primer carácter que permita admitir el depósito ordinario, sea civil o comercial, de títulos. La segunda exigencia es que el título sea infungible, porque el art. 2215 del $C C$ (también válido para el deposito mercantil) exige que el depositario restituya la cosa depositada "en especie" al depositante ${ }^{3}$; y la única manera de poderse cumplir tal exigencia es que ya la cosa depositada sea una "especie" ella misma, o sea, un infungible ${ }^{4}$.

El depósito de valores que constan en un "títulos" está, pues, sujeto a las reglas generales del depósito de corporales muebles, sea civil, sea mercantil. El presente trabajo no lo tiene por objetivo.

\section{El DePÓSito DE VAlORES, TITUlados O NO, EN UNA ENTIDAD DE DEPÓSITO Y CUSTODIA DE VALORES}

La ley $\mathrm{N}^{\circ} 18.876$ regula un especial depósito de valores, titulados o no, y es a él cual se destina el presente estudio.

Preliminarmente debemos tener presente que la literatura chilena sobre esta figura es muy escasa. Tan solo cabe destacar un libro de Pablo Mattar Oyarzún ${ }^{5}$, que trata del depósito de valores de oferta pública como parte de una exposición del sistema de la ley $\mathrm{N}^{\circ} 18.876$, aunque sin distinguir sus aspectos orgánicos y estructurales de los funcionales y dogmáticos. Resulta notorio el desinterés que han mostrado los autores por este tema, porque a la brevedad de literatura monográfica se añade que nada concerniente se encuentra en las exposiciones generales sobre los valores, titulados o no ${ }^{6}$. En el extranjero hay escrito algo más, pero debe ser usado con extrema cautela, porque las bases de la ley $\mathrm{N}^{\circ} 18.876$

${ }^{3}$ Sobre este punto véase GuZmán BRito (2014), cap. I, pp. 89-91.

${ }^{4} \mathrm{Si}$, por ejemplo, se trata de (títulos de) acciones depositadas, la identificación que constituye la infungibilidad del título está dada por su serie y número (véase el art. 11 del Regl. L. soc. anón).

${ }^{5}$ Mattar Oyarzún (1999), pp. 182-252.

${ }^{6}$ Así, por ejemplo, nada concerniente se encuentra en Novoa Galán-Novoa MuÑoz (1997), que solo mencionan la existencia de las empresas de depósito de valores en pp. 181-182; Baeza Ovalle (2008), iII, pp. 1335-1499; Lara Aguayo(2013); Sandoval López (2015), II. 
son distintas de las que suele adoptar la legislación foránea y, por ende, esta no sirve de autoridad en Chile ${ }^{7}$.

\section{Marco institucional en el cual debe celebrarse el depósito de valores}

El depósito de valores establecido en la ley $\mathrm{N}^{\circ} 18.876$ debe tener lugar en el marco de la actividad de las empresas de depósito de valores creadas por esa misma ley: especializado, es, pues, el depositario, pero también el depositante, lo mismo que el valor por depositar, como se verá enseguida. De esta manera, no es legalmente posible que el contrato descrito en la ley sea celebrado entre cualesquiera personas sobre cualquier valor; aunque de esta manera libre pueda, por cierto, ser celebrado un contrato ordinario de depósito, como se indicó en la Introducción.

\section{El depositario}

El depositario, según la ley, solo puede ser una sociedad anónima especial, que recibe el nombre de "empresa de depósito de valores", cuyo objetivo social exclusivo consista en "recibir en depósito valores de oferta pública" de ciertas entidades legalmente autorizadas para depositar; y de facilitar las operaciones de transferencia de dichos valores, en la forma fijada por la ley (art. 1 inc. $1^{\circ}$ de la ley $\mathrm{N}^{\circ}$ 18.876). A la fecha solo existe una de estas empresas, creada en 1993, que tomó el nombre de Depósito Central de Valores S.A; pero la ley no monopoliza la actividad en ella y en cualquier momento podría establecerse otra o varias compañías del género.

El estudio del procedimiento de constitución de estas sociedades y de su organización y funciones exceden los límites de este trabajo.

\section{Valores depositables}

a) Es natural que solo se pueden depositar "valores"; pero no es esta la sede para discutir qué sea un valor. De estos, empero, únicamente son depositables:

i) los valores de oferta pública inscritos en el Registro de Valores que lleva la Superintendencia de Valores y Seguros;

${ }^{7}$ Un panorama, breve e incompleto, de la legislación americana en RODRÍGUEz AzUERO (2009), pp. 267-270 y 297-302.

${ }^{8}$ El epígrafe de la ley las denomina "entidades privadas de depósito y custodia de valores". 
ii) Los valores de oferta pública emitidos por los bancos;

iii) Los valores de oferta pública emitidos por el Banco Central de Chile;

iv) Los valores de oferta pública emitidos por el Estado;

v) Los valores de oferta pública garantizados por el Estado y

vi) Cualquier otro valor de oferta pública que la Superintendencia de Valores y Seguros autorice mediante una norma general suya (art. 1 inc. $2^{\circ}$ de la ley $\mathrm{N}^{\circ} 18.876$ ).

Se observa que, aparte del requisito concerniente a quién sea el emisor o el garante, debe tratarse de "valores de oferta pública"; se excluye, por ende, a los valores de oferta no pública ${ }^{9}$ o no destinados a circular merced a una publicidad de su oferta ${ }^{10}$. Ahora bien, la expresión "oferta pública" aparece en la norma citada solo con respecto a los valores inscritos en el Registro de Valores que lleva la Superintendencia de Valores y Seguros; vale decir, adosada únicamente al primer ítem de los seis que enumera; en los casos restantes, el texto se limita a decir "valor" (por lo general en plural). Pero interpretamos que la exigencia de tratarse de un valor "de oferta pública" es aplicable a los cinco ítems restantes; y por eso hemos repetido la pertinente expresión también a propósito de cada uno de ellos ${ }^{11}$. La otra posibilidad fuere que, en los casos posteriores al primero, el valor depositable pudiera ser tanto de oferta pública como de oferta no pública, y aceptar, así, una asimetría evidente en el texto legal ${ }^{12}$. Pero se trata nada más que de una forma de omisión de cierta palabra o expresión, llamada 'elipsis', perfectamente aceptable y usual en el castella-

${ }^{9}$ Véase la norma de carácter general $\mathrm{N}^{\circ} 336$, de 27 de junio de 2012, de la Superintendencia de Valores y Seguros, sobre ofertas de valores que no se consideran públicas.

${ }^{10} \mathrm{El}$ art. 4 de la ley $\mathrm{N}^{\circ} 18.045$ define la oferta pública como "la dirigida al público en general o a ciertos sectores o a grupos específicos de éste".

${ }^{11}$ Téngase presente que el art. 5 letra b) de la ley $\mathrm{N}^{\circ} 18.045$ establece que todos los valores que sean de oferta pública se inscriben en el Registro de Valores que lleva la Superintendencia de Valores y Seguros; de modo de poder pensarse, según entendemos, en solo haber bastado el ítem $i$ ) y en ser superfluos los restantes; pero no es así, porque hay valores de oferta pública que están exentos de la inscripción, como los emitidos por bancos o sociedades financieras que operen en el país, a menos que se trate de sus propias acciones o bonos o de otros títulos que la Superintendencia de Bancos e Instituciones Financieras especialmente determine (ley $\mathrm{N}^{\circ} 18.045$, art. 69 inc. $3^{\circ}$ ).

${ }^{12}$ Refuerza esta conclusión que el texto diga "los" en los ítems $i i$ ) a v) ("los emitidos", "los emitidos", "los garantizados" [que suple la conjunción "o"]). Eso obliga a entender la elipsis de "valores de oferta pública" y no simplemente de "valores". Esto no vale para el ítem vi) "cualquier otro valor que"; pero igual se entiende la expresión "de oferta pública" añadida ahí a "valor", porque no de otros valores que de oferta pública se venía hablando y no se podría suponer la existencia de un tan brusco cambio de adjetivación que atribuir a "valor", del cual no se da indicio alguno. 
no ${ }^{13}$. De todos modos, interesará la interpretación que den a este punto la Superintendencia de Valores y Seguros ${ }^{14} \mathrm{y}$, eventualmente, la judicatura.

b) Conviene precisar que los valores depositables pueden constar en un título cartáceo, como consistir en una anotación en cuenta y estar, por ende, desmaterializados; lo cual vale pena advertir porque a veces se cree que el depósito de la Ley $\mathrm{N}^{\circ} 18.876$ solo atañe a los valores desmaterializados, lo cual no es así.

\section{c) El depositante}

La ley tipifica a los sujetos que pueden depositar valores de oferta pública en las empresas de custodia de valores. Vale decir, no cualquier persona que sea titular de esos valores puede hacerlos objeto de un tal depósito.

Así, pues, según la ley únicamente pueden depositar (art. 2 de la ley $\left.\mathrm{N}^{\mathrm{o}} 18.876\right)$ :

i) El fisco de Chile, a través de la Tesorería General de la República;

ii) El Banco Central de Chile ${ }^{15}$;

iii) La Corporación de Fomento de la Producción;

${ }^{13}$ Como cuando se dice: "A entró fumando y B, cantando", en vez de "A entró fumando y B entró cantando": en este caso, la elipsis afecta a la forma verbal 'entró', cuya omisión mantiene la inteligibilidad de la frase y es suplida por el contexto.

${ }^{14}$ Hasta la fecha, ese organismo ha emitido dos resoluciones sobre la materia, de las cuales la primera fue derogada, pero repetido su contenido en la segunda, de 23 de abril de 1999 (norma de carácter general N 81). Este última autoriza el depósito de "cuotas de fondos mutuos" ( $\left.\mathrm{N}^{\circ} 2\right)$. El $\mathrm{N}^{\circ} 1$ de la norma también autoriza el depósito de valores de oferta pública inscritos en el Registro de Valores que lleva la Superintendencia de Valores y Seguros (y repite lo que había establecido la norma de carácter general $\mathrm{N}^{\circ} 65$, de 14 de mayo de 1996). Pero esta última autorización emana directamente del art. 1 inc. $2^{\circ}$ de la ley $\mathrm{N}^{\circ} 18.876$, y no se necesitó ninguna norma de la Superintendencia que la otorgará, así que es superflua. Ahora bien, las cuotas de fondos mutuos, cuyo depósito es permitido por la norma de carácter general $\mathrm{N}^{\circ} 81$, son valores de oferta pública.

${ }^{15}$ La norma no dice que el fisco pueda depositar a través de la Tesorería General de la República y (c่o?) a través del Banco Central de Chile; sino que, como se indica en el cuerpo del texto, puedan depositar el fisco a través de la Tesorería; y además y aparte, el Banco Central. Se quiso dar legitimidad al fisco para depositar, pero resultaba natural que este lo hiciera a través de la Tesorería; o, bien, se quiso dar legitimidad a la Tesorería, pero como ella carece de personalidad jurídica, en realidad había que darla al fisco. Por otro lado, si la legitimidad fuera para el fisco a través de la Tesorería, el papel del Banco Central (que sí tiene personalidad jurídica), como se dijo, ¿sería copulativo ("a través de la Tesorería y el Banco") o alternativo ("a través de la Tesorería o el Banco")? Es claro, empero, que la letra a) del art. 2 de la ley $\mathrm{N}^{\circ} 18.876$ contiene dos legitimidades diferentes. Que así haya sido lo demuestra definitivamente el hecho de que la legitimidad del Banco Central fue añadida al texto original de la ley por art. $11 \mathrm{~N}^{\circ} 1$ letra a) de la ley $\mathrm{N}^{\circ} 19.705$ (DO. de 20 de diciembre de 2000). Por lo demás, la independencia del Banco Central para depositar es una exigencia específica de su autonomía garantizada por la Constitución Política. 
iv) Los agentes de valores;

v) Los corredores de bolsa;

vi) Las bolsas de valores;

vii) Los bancos, sociedades financieras y demás instituciones autorizadas para operar en Chile, de acuerdo con la Ley General de Bancos e Instituciones Financieras;

viii) Las administradoras de fondos mutuos;

ix) Las administradoras de fondos de pensiones;

$x$ ) Las compañías de seguros y de reaseguros establecidas en Chile;

xi) Las administradoras de fondos de inversión;

xii) Las administradoras de fondos de inversión de capital extranjero o su representante legal, si corresponde;

xiii) Las administradoras de fondos para la vivienda;

xiv) Las sociedades administradoras de sistemas de compensación y liquidación de instrumentos financieros y

$x v)$ Las demás entidades que autorice la empresa de depósito de valores donde se intenta depositarlos ${ }^{16}$.

Conforme con esto último, nada obsta a que una empresa autorice a un particular para ejecutar depósitos, en la medida en que se trate de valores de oferta pública.

En todo caso, la empresa debe levantar un "registro de depositantes" (art. 25 del Regl. L. dep. val.).

\section{Perfeccionamiento Del CONTRATO}

1. De acuerdo con el art. 3 de la ley $\mathrm{N}^{\mathrm{0}} 18.876$, el contrato de depósito "se perfecciona mediante la entrega de los valores a la empresa". La norma añade que tal entrega "se hará mediante las formalidades propias de la transferencia de dominio, según sea la naturaleza del título de que se trate" (lo cual es repetido por el art. 12 del Regl. L. dep. val.). De la combinación de ambas normas se colige que el depósito se perfecciona merced a una tradición, en oposición a cuanto se exige por Derecho Común, para el cual un depósito regular ordinario se perfecciona merced a una mera entrega (art. 2212 del $C C$., cfr. con el art. 2215). Para este, pues, el depósito traspasa la mera tenencia de la cosa depositada (cfr. con el art. 714 del $C C^{17}$ );

${ }^{16}$ No se trata, pues, que cualquier empresa de depósito de valores autorice el depósito en las demás; sino solo en ella misma.

${ }^{17}$ Esta norma no menciona al depositario (sí al secuestre) entre los meros tenedores, lo cual es inexplicable y atribuible a solo un olvido del redactor. Como es bien sabido, el depositario no puede prescribir ni ejercer las acciones posesorias, y pretender que no sería un mero tenedor sino un poseedor, porque no aparece mencionado en el art. 714 del 
para la ley en estudio, en cambio, aquel transfiere el dominio de los títulos depositados.

2. Como se acaba de ver, la ley reenvía a las formalidades establecidas para la transferencia de dominio del título según sea la naturaleza del que va a ser depositado. Por consiguiente, si el valor es "al portador", la entrega-transferencia en depósito debe hacerse mediante la entrega material del título; si es "a la orden", merced a su endoso (seguido de la entrega material); y si es nominativo, como indica el art. $1901 \mathrm{del} C C$ (cfr. con el art. 162 del $C$ Com $)^{18}$. En cuanto al endoso de letras de cambio y pagarés, ténganse presente las normas del párrafo $2^{\circ}$ del título $1^{\circ} \mathrm{de}$ la ley $\mathrm{N}^{\circ} 18.092$ (DO. de 14 de enero de 1982): "Dicta nuevas normas sobre letra de cambio y pagare". Y, por lo que concierne a otros títulos, adviértase que las reglas recién citadas de la ley $\mathrm{N}^{\circ} 18.092$ son aplicable a

"cualesquiera otros títulos de crédito de dinero emitidos con la cláusula 'a la orden', 'en favor de', 'a disposición de' u otras equivalentes, cualesquiera fuere la denominación con que se designare a dichos instrumentos",

por mandato del art. 1 inc. $1^{\circ}$ de la ley $\mathrm{N}^{\circ} 18.552$ (DO. de 29 de septiembre de 1986): "Regula tratamiento de títulos de crédito"; así que, con ello, las reglas sobre cesión de letras de cambio son de aplicación general a todos los títulos.

3. Se puede preguntar por cuál sea el título traslaticio de dominio de la tradición que perfecciona al depósito, puesto que el art. 678 del $C C$ exige uno para que valga la tradición. La respuesta es el crédito, porque, como se verá mejor después (v. el cap. x,4), el depósito convierte en fungibles los valores y un depósito de fungibles o irregular no es un depósito sino un crédito regidos por algunas reglas del depósito ${ }^{19}$.

4. El Regl. L. dep. de valores contiene un caso especial: que se convenga un depósito de títulos que no son entregados, sino con posterioridad ${ }^{20}$. Pero

CC. resultaría una insensatez. Los autores parecen no haber observado la omisión. Véase, entre los antiguos, a Claro Solar (1932/1992), viI, 2, párr. 819, pp. 469-472 y, entre los modernos, a Peñailillo Arévalo (2006), párr. 174, pp. 361-362. El único trabajo chileno sobre la mera tenencia, que es Pomés ANDrAde (1966), incluye sin más al depósito entre los casos que dan lugar a mera tenencia (pp. 49 y 52-53), pero tampoco se propone el punto de su omisión en el art. $714 \mathrm{del} C C$.

${ }^{18}$ En general, véase el título $4^{\circ}$ del libro II del CCom. (arts. 162 a 165).

${ }^{19}$ Sobre el particular, véase GuZMÁn Brito (2014), sec. viI, pp. 121-130.

${ }^{20} \mathrm{Regl}$. L. dep. de valores, art. 10: "El contrato de depósito de valores se otorgará por escrito y deberá contener, a lo menos las siguientes estipulaciones [...]/ b) 'Indicación del tipo de título que se entregarán en depósito'. Y añade: Para el caso de que los títulos se entreguen en ese acto al depósito, así como para las entregas posteriores que se efectúen 
eso, en realidad, no es un depósito, que, por mandato de la ley, exige la entrega actual de los títulos; de modo que la figura referida en el Regl. L. dep. de valores debe ser interpretado como una promesa de depósito de títulos, que se perfeccionará en el futuro con su entrega. El citado reglamento no menciona que esta promesa deba cumplir con los requisitos del art. $1554 \mathrm{del} C C$. Pero la omisión no puede ser interpretada como derogación de las exigencias de esa norma legal, inaceptable en un reglamento; así que esta promesa de depósito debe constar por escrito (lo cual el Regl. L. dep. de valores supone) y debe contener un plazo o una condición que fije la época de la celebración del depósito (o sea, de la entrega) ${ }^{21}$.

En cuanto a la individualización de los títulos, el Regl. L. dep. de valores establece una diferencia entre la promesa y el contrato: si la convención depositaria se ve acompaña de la entrega, vale decir, si el contrato se perfecciona una primera vez por esta, debe señalarse por escrito el tipo, especie, clase, serie y emisor de los valores y demás particularidades de los mismos; si, en cambio, se trata de la promesa, que, por ende, no va acompañada de la entrega, basta indicar el tipo de los títulos que se entregarán en depósito ${ }^{22}$, esto es, si se trata de acciones, bonos, depósitos, etc., así genéricamente indicados.

5. Cuando, en especial, se trata del depósito de acciones de sociedades anónimas -que solo pueden ser nominativas ${ }^{23}$ - o de cuotas de fondos de inversión -que también solo pueden ser nominativas ${ }^{24}-\mathrm{y}$, en ambos casos, los respectivos registros de accionistas o aportantes sean administrados por la empresa de depósito de valores o por una filial suya constituida de acuerdo con el art. 23 de la ley $\mathrm{N}^{\circ} 18.876$, a las cuales se confíe la custodia de los títulos, la entrega de estos "podrá" componerse:

i) de una instrucción dada a la empresa por el depositante a través de los medios escritos o electrónicos que señale el reglamento interno de la empresa y

ii) del acto de ejecución de la precedente instrucción recibida por la empresa o su filial, consistente en unas anotaciones simultáneas en

bajo el mismo contrato, se informará sobre el tipo, especie, clase, serie y emisor de los valores y demás particularidades de los mismos”.

${ }^{21}$ Téngase presente que la condición puede consistir en el hecho futuro de depositar, que vale según lo prescrito por el art. 1478 inc. $2^{\circ}$ del CC. En efecto, en el tráfico negocial puede ser difícil fijar un plazo u otra condición para perfeccionar el depósito; de ahí la utilidad de esta observación que, en el fondo, viene a validar una promesa de depositar para cuando se lo necesite.

22 Todo en el art. 10 letra b) del Regl. L. dep. de valores.

${ }^{23}$ Art. 12 de la ley $\mathrm{N}^{\circ}$ 18.046: "Sobre sociedades anónimas" (DO. de 22 de octubre de 1981).

${ }^{24}$ Art. 15 inc. $2^{\circ}$ de la ley $\mathrm{N}^{\mathrm{o}}$ 18.815: "Regula fondos de inversión" (DO. de 29 de julio de 1989). 
la cuenta que corresponda de las que mantenga el depositante, y en el registro del emisor respectivo (art. 3 inc. $3^{\circ}$ de la ley $\mathrm{N}^{\circ} 18.876$ ). La disposición dice que de esa manera tiene lugar la "entrega" de los títulos ("tal entrega se podrá hacer mediante"); y debemos entender que se mienta la entrega traslaticia a que se refiere el art. 3; así que, no bien nada se diga expresamente en orden a que haya transferencia de las acciones o de las cuotas de fondos de inversión, igual la se deduce, porque se habla de una entrega hecha merced al procedimiento prescrito. Fuere asistemático que, en este caso particular, el depósito no se constituyere mediante una transferencia en contra de lo dispuesto por el inc. $1^{\circ}$ del art. 3 .

6 . Fuera de los casos señalados por el art. 23 de la ley $\mathrm{N}^{\circ} 18.876$, es decir, cuando los respectivos registros de accionistas o aportantes no sean administrados por la empresa de depósito de valores o por una filial suya constituida de acuerdo con el art. 23 de la ley $\mathrm{N}^{\circ} 18.876$, rigen las reglas generales.

a) Por lo que atañe a las acciones, el art. 12 de la ley $\mathrm{N}^{\circ} 18.046$ sobre sociedades anónimas, dice: "La transferencia [de acciones] se hará en conformidad a dicho reglamento [de la ley] [...]". En efecto, el Regl. L. soc. anón. señala en su art. 38 inc. $1^{\circ}$ las siguientes formas de cesión o transferencias de acciones:

i) Instrumento privado firmado conjuntamente por el cedente y el cesionario ante un notario público; o

ii) Dos instrumentos privados firmados separadamente cada uno por el cedente y por el cesionario ante dos testigos mayores de edad; o

iii) Dos instrumentos privados firmados separadamente cada uno por el cedente y por el cesionario ante un corredor de bolsas; o

iv) Un instrumento privado firmado conjuntamente por el cedente y el cesionario ante dos testigos mayores de edad; o

v) Un instrumento privado firmado conjuntamente por el cedente y el cesionario ante un corredor de bolsa;

vi) Una escritura pública suscrita por el cedente y el cesionario ${ }^{25}$.

$\mathrm{El}$ art. 41 del Regl. L. soc. anón. agrega que la cesión de las acciones producirá efecto entre las partes desde su celebración y, respecto de la sociedad y de terceros, desde el momento de la inscripción del nuevo titular en el Registro de Accionistas ${ }^{26}$, a lo que la sociedad debe proceder

${ }^{25}$ El art. 39 del Regl. L. soc. anón. prescribe que si la cesión o transferencia de acciones tenga por antecedente (título o causa) su custodia es necesario cumplir con las mismas formalidades indicadas en el art. 38, pero deberá dejarse constancia del antecedente correspondiente en el instrumento por el que se celebre la transferencia.

${ }^{26} \mathrm{El}$ art. 7 del Regl. L. soc. anón. dispone: "[Inciso $\left.1^{\circ}\right]$ La sociedad anónima deberá llevar un Registro de Accionistas en el que se anotará, a lo menos, el nombre, domicilio y cédula nacional de identidad o rol único tributario de cada accionista, si lo tuviera, la 
en el momento en que tome conocimiento de la cesión. Si un notario o un corredor de bolsa ejecutan la notificación de la cesión a la sociedad y en el mismo acto entregan una copia del contrato de cesión y el título de las acciones a la sociedad ${ }^{27}$, se entiende que esta ha tomado conocimiento de la cesión y cualquier interesado puede demostrar este hecho -para los efectos a que haya lugar, por ejemplo, indemnización de perjuicio contra la sociedad-con solo invocar y probar la notificación y la entrega dichas.

b) En lo concerniente a las cuotas de fondos de inversión, el art. 11 inc. $1^{\circ}$ del Reglamento sobre administración de fondos de terceros y carteras individuales, aprobado por el decreto supremo $\mathrm{N}^{\mathrm{O}} 129$ (DO. de 8 de marzo de 2014, para regir desde el 1 de mayo del mismo año) dispone que la cesión, o sea, la transferencia de las cuotas de un fondo, en la generalidad de la cual dicción quedan, por cierto, comprendidas las cuotas de un fondo de inversión, pueda ser efectuada por instrumento privado extendido como dice la letra a) de la disposición citada, por escritura pública (letra b); y por

"aquellos sistemas físicos, electrónicos o mecánicos que las administradoras pongan para esos efectos a disposición de los aportantes y que cumplan los requisitos de seguridad establecidos por la Superintendencia mediante norma de carácter general" (letra c).

El inc. $2^{\circ}$ del art. 11 añade que la cesión de cuotas de fondos se notificará a la administradora en forma física o electrónicamente por el cedente de las cuotas a la administradora del fondo, y que las condiciones que han de cumplir los medios y sistemas que se emplearán para realizar las referidas notificaciones serán establecidas por la Superintendencia de Valores y Seguros mediante norma de carácter general. $\mathrm{El}$ inc. $3^{\circ}$ determina que la cesión no haya de producir efecto contra la administradora mientras esta no haya tomado conocimiento de la cesión, ni contra terceros mientras no haya sido anotada en el Registro de Aportantes.

7. El perfeccionamiento del contrato implica que los valores quedan registrados a nombre de la empresa de depósito, puesto que se los transfirió ${ }^{28}$.

serie, si la hubiere, y el número de acciones de que sea titular, la fecha en que éstas se hayan inscrito a su nombre y [...]./ [Inciso $3^{\circ}$ ] En caso que algún accionista transfiera todo o parte de sus acciones deberá anotarse en el Registro esta circunstancia”.

${ }^{27}$ A menos que este último estuviese en poder de la sociedad o esta no tuviera la obligación de imprimir láminas físicas de los títulos, previene la disposición.

${ }^{28}$ Aunque el registro a nombre de la empresa de depósito no es algo que aparezca dicho expresamente en la ley, deriva de la tradición que hubo de operar para el perfeccionamiento del depósito (art. 3 inc. $1^{\circ}$ ). Pero así se explicó en la sesión conjunta de las comisiones legislativas de la Junta de Gobierno, de 2 de agosto de 1989. El fiscal de la Superintendencia de Valores y Seguros, Pedro Mattar, dijo entonces: "En el emisor queda inscrito como titular de esos valores la empresa de depósito” (p. 11); y recalcó más adelante el profesor 


\section{Prueba y Contenido}

\section{DEL CONTRATO}

1. $\mathrm{El}$ art. 3 inc. $2^{\circ}$ añade: "El contrato constará por escrito". No debe interpretarse esta regla en el sentido de añadir una forma ad sollemnitatem a la entrega, para perfeccionar (doblemente) el contrato, de manera que sin su escrituración este fuere nulo absolutamente: dicha regla, en efecto, no dice que el contrato se perfeccione por escrito; solo se limita a mandar que haya de constar de tal manera. Por consiguiente, ella debe ser puesta en relación con el art. 1708 del $C C$ : "No se admitirá prueba de testigos respecto de una obligación que haya debido consignarse por escrito", donde la palabra 'obligación' está por "acto o contrato" y la forma verbal 'consignarse' por 'constar' ${ }^{29}$. De esta forma, el dispositivo del art. 3 inc. $2^{\circ}$ de nuestra ley, al ordenar que el contrato de depósito de valores de oferta pública conste por escrito, viene a disponer -merced al art. 1708 del $C C$ - que ese contrato no pueda ser probado por testigos ${ }^{30}$.

2. Pero no solo eso, porque el art. 2217 del $C C$ dispone que, cuando deba otorgarse por escrito el depósito, como es el caso presente, y se hubiera omitido tal formalidad "será creído el depositario sobre su palabra", tanto en orden al hecho mismo del depósito como en cuanto a la cosa (valor en este caso) depositada y al hecho de la restitución.

3. El art. 10 del Regl. L. dep. de valores dispone que el escrito en que conste el depósito pueda admitir toda clase de estipulaciones (se subentiende que lícitas) que las partes quieran acordar ${ }^{31} ; \mathrm{y}$ prescribe una serie

invitado a la sesión Raúl Varela: “[...] resulta inevitable que los títulos estén inscritos a nombre de la sociedad de depósito" (p. 13). Estas explicaciones no fueron contradichas en la oportunidad y es claro que se las miró cual deducción del sistema de la ley, como, de hecho, son. El expediente que contiene la documentación legislativa concerniente a la ley $\mathrm{N}^{\circ} 18.876$ se encuentra en la Biblioteca del Congreso Nacional.

${ }^{29}$ De hecho, mientras el art. 1708 usa el sustantivo 'obligación' y la forma verbal 'consignarse', el que le sigue inmediatamente, aplicando y concretando su mandato, dice: "Deberán costar por escrito los actos o contratos que contienen la entrega o promesa de una cosa que valga más de dos unidades tributarias". Aquí, pues, el Código usa 'constar' como sinónimo de 'consignar', y aclara que lo que ha de constar por escrito no es tanto la obligación cuanto el acto o contrato que la origina. La norma jamás ha sido entendida en otro sentido, ya desde la época de Claro Solar (1939/1992), XII, 3, párrs. 2097-2098, pp. 731-733.

${ }^{30}$ Por ende, el art. 10 del Regl. L. dep. de valores, en rigor parece excederse cuando expresa: "El contrato de depósito de valores se otorgará por escrito [...]", si la expresión "se otorgará" significara "se perfeccionará por escrito", porque no es así. Pero puede perdonarse esa redacción imperfecta si "se otorgará" se lee con el entendimiento de "constará" o "se consignará".

${ }^{31}$ Art. 10 letra j): "Las demás estipulaciones que las partes acuerden". 
de cláusulas que deben ser incluidas (“deberá contener, a lo menos"32). El citado reglamento no sanciona la omisión de estas cláusulas; pero es menester pensar en que su sanción es la imposibilidad de probárselas por medio de testigos.

\section{TIEMPO DEL CONTRATO}

El contrato admite ser celebrado por tiempo indefinido o por un plazo determinado; pero menester es declarar cada uno de estos casos ${ }^{33}$. Una vez celebrado por primera vez el contrato, en el futuro se puede entregar otros títulos a su amparo, vale decir, sin necesidad de celebrar una ulterior convención respecto de los nueva y últimamente entregados ${ }^{34}$. Pero debe advertirse que cada entrega constituye un nuevo contrato, atendido el modo en que este se perfecciona según la ley; solo que todos quedan amparados por la misma convención reguladora que sirve de marco.

De acuerdo con el Derecho Común, la cláusula por la cual se fija un plazo para el contrato de depósito, o sea, para la restitución de lo depositado, solo obliga al depositario, quien en virtud de ella no puede devolver el objeto antes del tiempo estipulado (art. 2226 inc. $2^{\circ}$ del $C C$ ); pero no obliga al depositante, en orden a tener que abstenerse de pedir la restitución antes de cumplido el plazo.

\section{Caracteres generales DEL CONTRATO DE DEPÓSITO DE VALORES DE OFERTA PÚBLICA}

De acuerdo con los términos con que la ley ha configurado el contrato de depósito de valores de oferta pública, este puede ser caracterizado como sigue:

i) Es bilateral, porque los contratantes se obligan recíprocamente (art. 1439 del $C$ C). La empresa depositaria se obliga a restituir otro tanto de valores homogéneos con respecto a los recibidos (art. 6 de la ley $\mathrm{N}^{\mathrm{O}}$ 18.876); y el depositante se obliga a remunerarle el servicio del depósito prestado (arts. 7 y 10 letra g] del Regl. L. dep. de valores).

${ }^{32}$ Art. 10 inc. inicial.

${ }^{33}$ Art. 10 letra h) del Regl. L. dep. de valores.

${ }^{34}$ Art. 10 letra b) del Regl. L. dep. de valores: "Para el caso de que los títulos se entreguen en ese acto al depósito, así como para las entregas posteriores que se efectúen bajo el mismo contrato [...]”; la letra c) adopta una formula muy similar. 
ii) De acuerdo con el defectuoso concepto establecido por el art. 1440 del $C C$, este contrato sería oneroso por ceder en utilidad de ambos contratantes y porque cada cual se grava en beneficio del otro. En realidad, su onerosidad deriva de la intervención de un precio como contraprestación de la guarda o custodia de los valores [arts. 7 y 10 letra g) del Regl. L. dep. val.]. En todo caso, queda superada la gratuidad del depósito ordinario (art. 2219 del $C C)$ y confirmada la del mercantil (art. 809 del CCom.). Pero no es en absoluto aplicable el art. 810 del CCom., según el cual, el depositario que hace uso de la cosa depositada, aun en casos permitidos por la ley o la convención, pierde el derecho a la retribución.

iii) Es conmutativo, pues la prestación de cada parte es mirada como equivalente a la de la otra (art. $1441 \mathrm{del} C C$ ).

iv) Es principal, ya que subsiste por sí mismo, sin necesidad de sustentarse en otro contrato (art. 1442 del CC).

v) Es real (art. $1443 \mathrm{del} C C$ ), porque se perfecciona merced a la tradición de los títulos de oferta pública por el depositante a la depositaria (art. 3 de la ley $\mathrm{N}^{\circ}$ 18.876: véase, más atrás, II, 4).

vi) Es un contrato irregular, puesto que recae sobre títulos-valor homogéneos o fungibles, de modo que al término del contrato no se restituyen los mismos títulos recibidos sino otros del mismo género (artículos 4 y 5 L. 18.876) ${ }^{35}$

\section{REgISTRO DE LOS VALORES DEPOSITADOS EN CUENTA Y HOMOGENEIDAD DE LOS MISMOS}

Sin perjuicio de que una vez ingresados los títulos-valor en el poder de la empresa de depósito, esta se haga su dueña por tradición, ella debe abrir una cuenta individual para cada depositante ${ }^{36}$. En ella ha de registrar los valores según capítulos, artículos o ítems separados; cada grupo de valores homogéneos debe ser registrado en un capítulo, artículo o ítem apartado e independiente de los demás. Se entiende por valores homogéneos los que sean idénticos ${ }^{37}$ en cuanto al tipo (de valor: si sean acciones, o cuotas de inversión,

${ }^{35}$ Sobre el depósito irregular en general, véase GuZMÁn BRITO (2014).

${ }^{36}$ Acerca de la anotación de los valores depositados, véase Caballero Germain (2014), pp. 296-299.

${ }^{37}$ La homogeneidad de varios títulos permite que la empresa solicite al emisor su refundición en uno o más; también puede pedir cuantas veces quiera el canje de los títulos refundidos; en ambos casos el emisor debe acceder a la solicitud (art. 10 de la ley $\mathrm{N}^{\circ} 18.876$ ). La primera medida es para disminuir el volumen de títulos físicos que guardar; la segunda, para facilitar su devolución, ya que tal vez la empresa haya de restituir fracciones de la cantidad total de títulos los refundidos. 
o bonos, etcétera), especie, clase, serie y emisor ${ }^{38}$. Puede acaecer que ciertos valores hayan sido gravados con derechos reales o estar sujetos a embargos o a medidas precautorias. Cada una de estas circunstancias es bastante para dar lugar a un ítem separado de los demás dentro de la cuenta única del depositante que corresponda; pero hace perder homogeneidad respecto de los demás de su mismo tipo, especie, clase, serie y emisor no sujetos a derechos reales, embargos o medidas precautorias (todo en el art. 4 inc. $1^{\circ}$ segmento segundo de la ley $\mathrm{N}^{\circ}$ 18.876; véase el art. 34 del Regl. L. dep. val.).

La relevancia que la ley da a la homogeneidad de los valores depositados por sobre sus notas particulares individualizantes -que los valores de todos modos poseen, como un número de serie, etcétera- permite hablar de una fungibilidad legal de los valores ${ }^{39}$. Sean cuales fueren las notas

${ }^{38}$ Este despliegue de conceptos no definidos ofrece problemas de entendimiento. PugA VIAL (2013), I, pp. 226, 191-230, con referencia a la "clase de acciones", entiende por tal a los grupos de acciones que ofrecen determinados derechos o restricciones distintos a los de otro grupo de acciones de la misma sociedad emisora. En cambio, dice que se habla de "series de acciones" a los grupos de acciones que detentando los mismos derechos, limitaciones y características, tienen distinto valor nominal o que no teniéndolo fueron de hecho colocadas a un valor distinto a otro grupo de acciones. Distingue entre las clases de acciones a las en reserva, suscritas, pagadas y rescatables, según su forma de transferencia, según se paguen con recursos de la propia sociedad o con recursos de terceros o si son ordinarias y privilegiadas o preferentes. No obstante lo señalado por Juan Puga Vial, cabe precisar que la ley $\mathrm{N}^{\circ} 18.045$ sobre "Mercado de valores", se refiere específicamente a clases de acciones, cuotas de fondos de inversión u otros valores de deuda, a propósito de la clasificación por nivel de riesgo del valor. Tratándose de acciones y cuotas de fondo de inversión (art. 91) se clasifican en primera y segunda clase o sin información suficiente. En el caso de títulos de deuda (art. 88), se clasifican por categorías, en el caso de los de largo plazo de AAA a E, y aquellos de corto plazo de N1 a N5. Por ejemplo, el art. 69 bis de la ley $\mathrm{N}^{\circ} 18.046$ sobre sociedades anónimas, cuando hace referencia a acciones clasificadas en primera clase se remite a las normas de la ley $\mathrm{N}^{\circ} 18.045$. Por lo señalado, una interpretación posible del concepto de “clase" que utiliza el art. 4 de la ley $\mathrm{N}^{\circ} 18.876$, es entender esa referencia hecha a la clasificación de riesgo que el valor posea, lo que se refuerza en el hecho que la ley $\mathrm{N}^{\circ} 18.876$ se refiere a valores de oferta pública, respecto de los cuales es indispensable para el correcto funcionamiento del mercado, conocer su clasificación de riesgo. Sin embargo, el art. 4 de la ley $\mathrm{N}^{\circ} 18.876$ en su primera parte, señala: "La empresa de depósito llevará una cuenta individual para cada depositante, en la cual registrará, en ítem separados, cada clase de valores homogéneos que aquél mantenga en depósito", con lo cual claramente no parece referirse el legislador a la clase en cuanto clasificación de riesgo, sino que al mismo "tipo" o "especie" de valores de un depositante, de modo que se produzca la fungibilidad de los mismos, lo que denota un uso indistinto de las expresiones, que se podría haber resumido en que los valores sean iguales, en cuanto a su emisor y características y derechos asociados a la emisión.

${ }^{39}$ Que es similar a la fungibilidad de los billetes que emite el Banco Central (y originalmente cualquier banco, por el oro depositado en ellos, de modo que eran verdaderos títulos-valor). Cada billete lleva un código alfanumérico propio y singular que, en realidad, lo convierte en infungible. Pero en el tráfico jurídico ordinario no se toma en cuenta ese 
que permiten individualizar y distinguir a los valores como especies, la ley -atendiendo al tipo, especie, clase, serie y emisor de los valores- los considera como inidentificables y sustituibles e intercambiables entre sí, vale decir, como fungibles.

\section{DifERENTES CALIDADES \\ QUE PUEDE ASUMIR EL DEPOSITANTE}

1. El depositante pueda contratar el depósito de valores de oferta pública en nombre y por cuenta propios, en nombre propio y por cuenta ajena o en nombre y por cuenta ajenos; una cuarta posibilidad, que el depósito sea en nombre ajeno y por cuenta propia, es solo una posibilidad lógica sin proyección real.

El depósito de valores en nombre y por cuenta propios importa dos variantes:

i) que quien va a depositar los valores declare a la empresa ser su titular y lo sea de verdad;

ii) que quien va a depositar los valores declare a la empresa ser su titular sin serlo de verdad.

86 Da lo mismo que el depositante se declare titular de los valores (séalo o no) o que nada diga sobre el punto al depositarlos, pues en este último caso se lo trata como si hubiera declarado ser el titular.

Si el que va a depositar unos valores declara a la empresa que no son de su pertenencia y no identifica al titular, la operación consiste en un depósito en nombre propio mas por cuenta ajena.

Cuando, en fin, el que va depositar valores declara a la empresa que no son de su pertenencia e identifica al titular, el caso corresponde a un depósito por cuenta y a nombre ajenos.

Estas diversas modalidades tienen importancia para determinar la legitimación y la responsabilidad del depositante con respecto a diversos actos que atañan a los valores depositados.

2. En este momento únicamente se hace referencia a dos singularidades generales.

a) El art. 179 inc. $1^{\circ}$ de la ley $\mathrm{N}^{\circ} 18.045$, "De mercado de valores", incorporado ahí por el artículo primero $\mathrm{N}^{\mathrm{o}} 18$ letra b) de la ley $\mathrm{N}^{\mathrm{o}} 19.301^{40}$, expresa:

código y los billetes resultan ser fungibles, pues en todo lo demás son iguales entre sí. Esta fungibilidad es perfecta entre los billetes del mismo valor; pero funciona, incluso, entre los de valores diferentes, precisamente porque en los billetes lo que cuenta es el valor, que permite unas equivalencias, sentido en el cual un billete de $\$ 20.000$ es fungibles con dos de $\$ 10.000$ o con veinte de $\$ 1.000$ y hasta con dos mil monedas de $\$ 10$.

${ }^{40}$ DO. de 19 de marzo de 1994. 
"Los agentes de valores, corredores de bolsa, bolsas de valores, bancos, o cualquier otra entidad legalmente autorizada, que mantenga valores por cuenta de terceros pero a nombre propio, deberá inscribir en un registro especial y anotar separadamente en su contabilidad estos valores con la individualización completa de la o las personas por cuenta de quien los mantiene. Este registro hará fe en contra de las personas señaladas, pudiendo los interesados reclamar en todo tiempo sus derechos, valiéndose de cualquier medio de prueba legal”.

Como se ve, la norma impone a los agentes de valores, corredores de bolsa, bolsas de valores, bancos o cualquier otra entidad legalmente autorizada, se entiende que para custodiar valores, y que de hecho mantenga valores por cuenta de terceros, pero a nombre propio dice el texto, el doble deber de inscribir en un registro especial esos valores y de anotarlos de manera separada en su contabilidad, con la individualización completa de las personas por cuenta de quien los mantiene. La norma solo vale para los valores de terceros tenidos por una entidad a nombre propio; no, pues, para los valores de terceros tenidos por cuenta de ellos (vale decir, por cuenta ajena). Ella, empero, equivale a eliminar la categoría a que se aplica, porque si el tenedor debe inscribir los valores ajenos que tiene y anotarlos por separado en su contabilidad, con ello dejan de ser tenidos por nombre propio y empiezan a ser tenidos por cuenta ajena y en nombre ajeno: esto último es fácilmente verificable al examinar el registro especial y la contabilidad. La norma añade que el registro especial de los valores hace plena prueba contra "las personas señaladas", y se presenta el problema de saber a quiénes se mienta con esta expresión: Si a los agentes de valores, corredores de bolsa, bolsas de valores, bancos o cualquier otra entidad legalmente autorizada, que mantenga valores por cuenta de terceros, pero a nombre propio, sobre las cuales pesa el deber de llevar el registro de los valores que tengan por cuenta de terceros; o a la o las personas por cuenta de quienes se mantiene los valores. Aunque por gramática debería tratarse de estas, porque son las mencionadas más de forma más cercana a la expresión "las personas señaladas", jurídicamente se trata de las primeras. Nada especial es necesario probar contra los titulares de valores por cuenta de los cuales otro los tiene; por el contrario, a ellos interesa demostrar que sus valores son tenidos por agentes de valores, corredores de bolsa, bolsas de valores, bancos o cualquier otra entidad legalmente autorizada; y a ello provee el registro de esos mismos valores levantado por los tenedores mismos. Si el gravado con el levantamiento del registro no cumple con su deber o lo cumple imperfectamente y, aunque lo cumpla de modo perfecto los "interesados" -añade la norma- 
siempre ("en todo tiempo") podrán reclamar sus derechos, por cualquier medio de prueba legal. Es decir, los propietarios de los valores que por cuenta propia tiene un agente, un corredor, una bolsa, etcétera, siempre puede invocar su propiedad sobre tales valores y probarla por cualquier medio; y ello, incluso, aunque exista el registro especial aludido por la ley; el cual no es, pues, probatoriamente excluyente. Ahora bien, si existe y fue llevado de forma correcta, el interesado no necesita recurrir a otros medios, porque aquel prueba por sí solo contra el tenedor ${ }^{41}$.

b) El inc. $2^{\circ}$ del art. 179 de la ley $\mathrm{N}^{\circ} 18.045$ incorpora una segunda carga, pues expresa:

"Las personas indicadas en el inciso anterior que mantengan en su custodia valores de terceros, deberán abrir una cuenta destinada al depósito de dichos valores en una empresa de depósito y custodia de valores regulada por la ley $\mathrm{N}^{\circ} 18.876$. No obstante lo anterior, en el caso que los dueños de dichos valores así lo requieran, el intermediario deberá abrir cuentas individuales a nombre de aquéllos".

Las "personas indicadas" son los agentes de valores y corredores de bolsa, las bolsas de valores, los bancos o cualquier otra entidad legalmente autorizada para custodiar valores. $\mathrm{Si}$, de hecho, mantengan valores por cuenta de terceros, sea a nombre propio, sea a nombre ajeno, porque la ley, a diferencia de como procede en el inc. $1^{\circ}$, en este inc. $2^{\circ}$ solo dice "que mantengan en su custodia valores de terceros", sin añadir "por cuenta propia", deben depositar esos valores en una empresa de custodia de valores de las regidas por la ley $\mathrm{N}^{\circ} 18.876$. En principio, la cuenta de depósito puede ser abierta a nombre del agente, corredor, etcétera, que el segmento final del inc. $2^{\circ}$ denomina "intermediario". Pero cuando el dueño de los valores (por cuenta de quien los tiene el intermediario) lo requiera, el intermediario deber abrir cuentas individuales a nombre de cada dueño. La norma no es muy congruente con el sistema de la ley $\mathrm{N}^{\circ}$ 18.876 , porque viene a permitir que pueda aparecer como depositante una persona que no necesariamente está legitimada para depositar, si el dueño de los valores, quien requiere que la cuenta de depósito se abra a su nombre, no es una de las entidades enumeradas por el art. 2 de la ley y es, por ejemplo, persona natural particular, una sociedad, una corporación o una fundación.

${ }^{41} \mathrm{El}$ "registro especial de valores" es privado del ente obligado a levantarlo; y no está sometido a formalidades; la ley solo exige -y no es una formalidad sino una exigencia completamente lógica, si de un registro se trata- la individualización completa de la o de las personas por cuenta de quién son mantenidos los valores. 


\section{DOMINIO, PROPIEDAD O TITULARIDAD DE LOS VALORES}

1. Un punto importante en la dogmática del contrato de depósito de valores atañe al dominio o la propiedad de los valores depositados ${ }^{42}$. Hablamos de "dominio o propiedad" de tales valores. Esos términos, usados en el sentido del art. 582 del $C C$, son correctos cuando se los aplica al soporte material del valor ("título"), porque la disposición citada los define para mentar un derecho real en cosa corporal, y el soporte material de los títulos-valor es precisamente una cosa corporal. La corrección falla cuando se pretenda aplicarlos a los valores desmaterializados que, por definición, carecen de soporte material y solo constan en una anotación contable, a menos de pretenderse que esta es una cosa corporal, lo que difícilmente se puede pretender sin incurrir en un abuso del lenguaje jurídico. También falla cuando se los aplica al valor o derecho mismos, estén incorporados en un título o hayan sido desmaterializados, porque los derechos son cosas incorporales (art. 565 inc. $3^{\circ}$ ) y sobre ellos no puede haber dominio que solo es sobre corporales (art. 582 del $C$ C). Sobre los derechos en que los valores consisten, en cambio, hay una especie de propiedad (no una especie de dominio o propiedad del definido en el art. 582 del $C C$ ), que en la tradición se llama "cuasidominio". La denominación todavía fue empleada en el art. 688 del "Proyecto de 1853", pero abandonada durante su revisión posterior, de manera de haber desaparecido en el "Proyecto inédito" ${ }^{43}$. Se la puede recurrir, sin embargo, como término doctrinario técnico para designar la titularidad o pertenencia de un derecho, en nuestro caso, de un valor.

La ley $\mathrm{N}^{\circ} 18.876$ habla de "propiedad", “dominio" y "propietario" con respecto a los valores ${ }^{44}$. Como la referencia de las correspondientes normas es general y no solo a los títulos, si se pretende que con estos términos ellas hagan alusión al el derecho descrito por el art. 582 del $C C$

${ }^{42}$ Sobre esta materia ha tratado Caballero Germain (2013), quien explica el fenómeno del cual se dará cuenta en las líneas que siguen sobre la base de una copropiedad pro diviso ( $\dot{c}$ ?) de todos los depositantes de valores homogéneos sobre el conjunto de estos y que la empresa de depósito es un fiduciario, en el sentido de un "trustee" (fiduciario) en el "trust" del Derecho anglosajón. La hipótesis, que en todo caso exigiría un mayor desarrollo, no está mal pensada, pero no se puede aceptar que una figura del Derecho chileno sea explicable por figuras de derechos extranjeros que en su generalidad no han sido recibidas en Chile (¿̇alvo para el caso de este depósito?). En la historia fidedigna de la ley $\mathrm{N}^{\circ} 18.876$ el "trust" no fue mencionado y, aunque alguien habló de copropiedad (pro indiviso), fue una opinión aislada y fundada en el depósito alemán (véase, más adelante, el $\mathrm{N}^{\mathrm{o}} 5$ de este capítulo).

${ }^{43}$ Sobre todo lo anterior, véase GuZmán BRITo (2006), cap. 5º pp. 119-152.

${ }^{44}$ Ley $\mathrm{N}^{\circ} 18.876$, arts. 5 inc. $2^{\circ}$ y 17 ("propiedad"); 5,6 y 8 (“dominio") y 5 ("propietario"). 
(propiedad o dominio en cosa corporal) ese lenguaje es sin más erróneo, por lo ya expresado. Pero se puede interpretar que la mención es a la especie de propiedad (cuasidominio) del art. 583 del $C C$, en el cual no habría error ${ }^{45}$. En todo caso, es claro que, en otra terminología, la referencia es a la titularidad o pertenencia de los valores.

2. En relación con la propiedad (cuasidominio o titularidad) de los valores el art. 5 de la ley $\mathrm{N}^{\circ} 18.876$ distingue la empresa y el depositante, por un lado; y la empresa, el emisor de los valores y los terceros, por otro.

i) Considerados la empresa depositaria y el depositante, la norma citada tiene a este último como propietario (cuasidueño o titular) de los valores depositados a su nombre en la empresa;

ii) Considerados, en cambio, la empresa depositaria, el emisor de los valores depositados y los terceros, la misma norma tiene a la empresa como propietaria (cuasidueña o titular) de los valores depositados en ella (salvo las excepciones legales, como en materia de ejercicio de los derechos políticos y patrimoniales: v. el cap. $\mathrm{x})$, aunque advierte que esto no significa que el depositante o su mandante, si fuere el caso, dejen de tener el dominio (cuasidominio o titularidad) de los valores depositados para -añade- el ejercicio de los llamados "derechos políticos" y patrimoniales a que den lugar los valores, cuando corresponda. Esta advertencia limita el sentido del dominio (cuasidominio o titularidad) del depositante o su mandante, porque él es únicamente -como está dicho en la ley- para el ejercicio de los derechos políticos, vale decir, no es absoluto, como veremos más adelante.

3. Este régimen plantea problemas graves para la dogmática tradicional del Derecho Civil.

a) La ley dice que el contrato de depósito se perfecciona por una entrega (entre vivos, por supuesto) traslaticia de dominio, vale decir, por el modo de adquirir llamado tradición. Pero después dice que la transferencia y adquisición del dominio (cuasidominio o titularidad) operadas por esta tradición conciernen solo a las relaciones de la empresa depositaria con el emisor de los valores y los terceros, pero no a las del depositante con la empresa depositaria.

b) Por consiguiente, queda configurada una propiedad (cuasidominio o titularidad) que no es absoluta, sino relativa: con respecto a una misma

${ }^{45}$ Debe advertirse, con todo, que una discusión acerca de la corrección del uso de estos términos no se dio en el seno de las comisiones legislativas de la Junta de Gobierno que sesionaron conjuntamente para dar la versión del proyecto de la entonces futura ley $\mathrm{N}^{\circ} 18.876$, que fue aprobada por dicha Junta. La lectura de las actas de sus sesiones no da la impresión de que los miembros de esas comisiones hayan tenido siquiera en mente el tema de la terminología aplicable. 
cosa, el propietario (cuasidueño o titular) es tal frente a determinadas personas, pero no frente a otras.

c) Como los valores depositados empiezan a ser homogéneos o fungibles, con independencia de sus notas individualizantes; y como en las relaciones de la empresa depositaria con el emisor de los valores y los terceros aquella es mirada como dueña (cuasidueña o titular), se tipifica una propiedad (cuasidominio o titularidad) sobre fungibles que técnicamente es inadmisible -los fungibles, como son inidentificables y confundibles, no pueden ser vindicados-; tan inadmisible como la propiedad (cuasidominio o titularidad) del depositante sobre los valores depositados en poder de la empresa y frente a esta.

d) El depositante está legitimado por la ley para transferir a terceros el dominio (cuasidominio o titularidad) de los valores depositados (arts. 7 y 8 de la ley $\mathrm{N}^{\mathrm{o}} 18.876$ ) y para constituir derechos reales sobre ellos en favor de terceros (art. 14 de la ley $\mathrm{N}^{\mathrm{O}} 18.876$ ), aunque frente a los terceros en favor de quienes ejecuta la transferencia o constitución el transferente o constituyente -en suma, el depositante- no sea dueño (cuasidueño o titular) de los objetos de la transferencia o de la constitución; eso significa que el depositante ejecuta a non (quasi) domino ambos actos.

e) La empresa puede disponer de los valores recibidos en depósito, y está legitimada, por ejemplo, para darlos a otro depositante si sean valores homogéneos a los recibidos de él, cuando fuere menester restituírselos, sin que quepa aceptar la protesta del depositante; todo eso, pese a que la empresa, según dice la ley, frente al depositante no es la dueña (cuasidueña o titular) de los valores recibidos de él, así que también los dispone a non (quasi) domino.

f) Si el depositante a nombre propio fuera dueño de los valores depositados podría, en caso de un procedimiento concursal de liquidación, ejercer a su respecto la acción prevista en el art. 151 de la ley $\mathrm{N}^{\circ} 20.720$ : "De reorganización y liquidación de empresas y personas" (DO. de 9 de enero de 2014), que es llamada de "reivindicación" ahí; y que dispone:

"Podrán ser reivindicados los efectos de comercio y cualquier otro documento de crédito no pagado y existente a la fecha de dictación de la resolución de liquidación, en poder del deudor o de un tercero que los conserve a nombre de éste, y siempre que el propietario los haya entregado o remitido al deudor por un título no traslaticio de dominio".

La norma autoriza la "reivindicación" de "efectos de comercio" y otros "documento de crédito" (en las condiciones que señala) en poder del deudor siempre que el propietario los haya entregado por un "título no 
traslaticio del dominio" (por lo cual es muy discutible que esta acción, contra un tenedor sea propiamente de reivindicación, tema que ahora no interesa). Ahora bien, como el depósito de la ley $\mathrm{N}^{\circ} 18.876$ se perfecciona por una tradición y esta, para valer, necesariamente ha de tener un título traslaticio de dominio (art. 675 del $C C$., que, en el caso, es el crédito), he ahí que no puede haber la acción prevista en los términos del citado art. 151 de la ley $\mathrm{N}^{\mathrm{o}} 20.720$, que habla de entrega o remisión a "título no traslaticio de dominio" (depósito ordinario, comodato, arrendamiento, prenda). Pero no se entiende un dueño privado de la acción del art. 151, antes transcrito, destinada a reclamar lo suyo.

4. Tan antisistémica disciplina, que parece ser único en el mundo ${ }^{46}$, puede superarse cuando se considera que un depósito de fungibles (que se llama irregular ${ }^{47}$ ) necesariamente transfiere la pertenencia de lo depositado al depositario, hace que el depositante se convierta en un deudor y el depositante en un acreedor, en ambos casos de otro tanto de cosas del mismo género, así que tal clase de contrato es, en realidad, un crédito que se rige por algunas reglas del depósito. En tales circunstancias, el texto del art. 5 de la ley $\mathrm{N}^{\mathrm{o}}$ 18.876, habría que leerlo como si dijera:

"En las relaciones entre la empresa y el depositante, éste es [el propietario] 'un acreedor' de los valores depositados a su nombre. Ante el emisor de los valores y terceros, salvo las excepciones que se contemplan en esta ley, la empresa es considerada [dueña] 'deudora' de los valores que mantiene en depósito [, lo que no significa que el depositante o su mandante, en su caso, dejen de tener el dominio de los valores depositados, para el ejercicio de los derechos políticos y patrimoniales, cuando corresponda]"48.

De la última frase "lo que no significa-corresponda" puede prescindirse ${ }^{49}$ porque no hace más que anticipar lo que expresa mejor el art. 12. De que el depositante sea un acreedor de la empresa emana que esta sea su deudora de los valores.

${ }^{46}$ En los extremos se sitúan el art. 957 del CCom. de Honduras, según el cual el depósito de títulos fungibles (en un banco) transfiere la propiedad de los títulos al depositario; y el art. 276 de la Ley General de Títulos y Operaciones de Crédito de México, para la cual el depósito bancario de títulos no la transfiere.

${ }^{47}$ Véase el trabajo citado en la n. 3.

${ }^{48}$ Trata este tema GuZMán Brito (2015b), pp. 573-589.

${ }^{49} \mathrm{Y}$ si no se prescindiera fuere necesario leer la frase: "dejen de tener el dominio de los valores depositados" como si la norma dijere: "dejen de tener el dominio de "el crédito sobre' los valores depositados" (cfr. con el art. 583 del $C C$ : dominio de las cosas incorporales, de las que un crédito es especie). 
Con esta lectura, los problemas dogmáticos enumerados precedentemente desaparecen del todo. Por consiguiente, debe considerarse que el depósito de valores es un depósito irregular, que transfiere la pertenencia (cuasidominio o titularidad) de los valores a la empresa, que empieza a deberlos en cuanto al tantumdem, del cual el depositante se hace su acreedor. La empresa está obligada a restituir valores, pero no los mismos que recibió sino solo otro tanto homogéneo o fungible (art. 6 de la ley $\mathrm{N}^{\mathrm{o}}$ 18.876).

Como consecuencia de ello cabe sostener que la empresa depositaria se hace titular absoluta de los valores que recibió en depósito y que el depositante pierde su titularidad. En contrapartida, como quedó dicho, la primera se hace deudora de otro tanto de valores fungibles y el segundo, acreedor de lo mismo.

Pese a ello, la ley atenúa las consecuencias estrictas de tal premisa, que consistirían en atribuir a la empresa depositaria los "derechos políticos" y patrimoniales conferidos por el valor. En vez de ello, los conserva en cabeza del depositante a nombre propio o de su mandante, pese a no ser estos titulares de tales valores. Pero de estos trataremos aparte (v. el cap. X).

5. Conviene exponer cómo se afecta a la titularidad del depositante sobre sus valores en Alemania, donde se originó, a fines del siglo XIX, la operación consistente en el depósito de valores, en términos muy cercanos a cómo se considera en la actualidad.

El punto, entre tantos otros, aparece regulado en la Gesetz über die Verwahrung und Anschaffung von Wertpapieren ("Ley sobre depósito y adquisición de títulos-valor"), de 4 de febrero de 1937, que de forma usual se la abrevia como $\operatorname{Depot} G^{50}$. En realidad, esta ley distingue varios tipos de depósito y, en consonancia, varios efectos sobre la titularidad de los mismos.

i) Un tipo es el que la ley llama Sonderverwahrung ("depósito separado"), que aparece en su $\S 2$, según el cual el depositario debe mantener separados o apartados los títulos ${ }^{51}$ depositados con respecto a los propio y a los de terceros, mediante señales externamente reconocibles (de hecho, se los ata con una cinta de papel). Se trata, pues, de que los títulos recibidos por el depositario no se confundan con otros que ha recibido o recibirá. Por ello se trata de un ordinario depósito regular. En consecuencia, el depositante permanece como titular de los valores depositados y, al término de la custodia, puede exigir la restitución de los mismos títulos físicos que entregó.

${ }^{50}$ Un panorama sobre la regulación alemana en RAMíREz BAQUERO (2006), pp. 572-595.

${ }^{51}$ De modo que este tipo de depósito solo es aplicable a los títulos, no a los valores desmaterializados. 
ii) El segundo tipo viene denominado Unregelmäßige Verwahrung (“depósito irregular"). A él atañe el $\S 15$ de la DepotG. Consiste en convenir (de manera expresa y por escrito) el depositante y el depositario de valores que la titularidad de estos pase de inmediato al último de los indicados (o a un tercero) y que el depositario quede obligado a restituir, no los mismos títulos entregados, sino otros de su misma clase en la cantidad recibida al principio. Por consiguiente, a diferencia de cuanto acaece en el Sonderverwahrung, precedentemente examinado, el depositante pierde la titularidad de los valores depositados, que adquiere el depositario. El número 3 del $§ 15$ asimila el préstamos de valores a las reglas de su depósito irregular $^{52}$.

iii) Un tercer tipo de depósito es denominado Tauschverwahrung ("depósito-cambio" o "depósito-permuta”) por el $\$ 10 \mathrm{~N}^{\mathrm{o}} 1$; y mediante él el depositante, expresamente y por escrito, faculta al depositario para que le restituya, en vez de los mismos títulos que le entregó, otros de la misma clase en la cantidad original ${ }^{53}$. Aunque la ley no lo diga de manera expresa, se subentiende que este depósito no es irregular, como el tratado antes, ni del cuarto tipo que veremos, sino del primero ya visto, por lo cual el depositante conserva la titularidad de los valores depositados, que no adquiere el depositario, salvo que este último haga uso de la autorización conferida y restituya otros valores de la misma clase de los recibidos, pues entonces el depositante pierde la titularidad de los entregados, que adquiere el depositario, y gana la titularidad de los diversos recibidos ${ }^{54}$.

Un número 2 del párrafo 10 de la DepotG. expresa:

"Derselben Form bedarf eine Erklärung, durch die der Hinterleger den Verwahrer ermächtigt, hinterlegte Wertpapiere durch Wertpapiere derselben Art zu ersetzen" ("La misma formalidad necesita

${ }^{52}$ DepotG., $\S 15 \mathrm{~N}^{\mathrm{o}}$ 3: "Diese Vorschriften gelten sinngemäß, wenn Wertpapiere jemandem im Betrieb seines Gewerbes als Darlehen gewährt werden" ("Estas prescripciones valen análogamente cuando se otorga títulos-valor como préstamo a alguien en el ámbito de su empresa").

${ }^{53}$ DepotG, § 10,1: "Eine Erklärung, durch die der Hinterleger den Verwahrer ermächtigt, an Stelle ihm zur Verwahrung anvertrauter Wertpapiere Wertpapiere derselben Art zurückzugewähren, muß für das einzelne Verwahrungsgeschäft ausdrücklich und schriftlich abgegeben werden" ("Una declaración por la cual el depositante autoriza al depositario a restituirle, en lugar de los títulos-valor confiados en depósito, títulos-valor de la misma clase, debe ser librada expresamente y por escrito para el negocio de depósito singular").

${ }^{54}$ De ahí el nombre dado a esta operación, porque se produce una suerte de cambio o permuta de los valores entregados por los recibidos. 
una declaración por la cual el depositante faculta al depositario para sustituir los títulos-valor depositados por títulos-valor de la misma clase").

Parece que la diferencia con la regulación general de este tipo de depósito radica en que, según esta, la autorización es concedida al principio, mientras que la regulación especial del número 2 atañe a títulos ya depositados ("hinterlegte Wertpapiere").

iv) En fin, la Depot $G$ reconoce un cuarto tipo de depósito en su $§ 5,1$, que llama Sammelverwahrung ("depósito reunido, acumulado o colectivo"). Él debe recaer sobre títulos-valor fungibles (vertretbare Wertpapiere), siempre que el depositante no haya exigido que el depósito sea separado a su respecto [véase el $i$ )] y solo compete a una institución dedicada también a tal tipo de depósitos. El principal rasgo caracterizador de esta operación radica en que, desde el mismo momento en que sea celebrada, los títulos-valor fungibles sobre que recayó ingresan en una comunidad por cuotas (copropiedad: "Miteigentum nach Bruchteilen" dice la ley), vale decir, pro indiviso, constituida por ellos y el conjunto de los demás valores fungibles a su respecto, que también se encuentren depositados (DepotG, § 6). La determinación cuantitativa de las cuotas se hace según el valor nominal de los títulos-valor; si carecen de él, según su número ${ }^{55}$. Cada depositante puede exigir la entrega en restitución, no de los mismos títulos que depositó, sino de otros fungibles con aquellos, según su cuota (DepotG., § 7,1), determinada como acaba de decirse. El depositario está legalmente autorizado para extraer del fondo común de títulos las cantidades necesarias para satisfacer la restitución solicitada, sin necesidad de pedir autorización a los partícipes en la comunidad (DepotG., $\S$ $6,2)$. Si el fondo común ha sufrido pérdidas (como consecuencia, por ejemplo, de la disminución de valor nominal de los títulos), la merma la sufre el depositante, en el sentido de que la devolución

${ }^{55}$ DepotG, § 6,1: "Für die Bestimmung des Bruchteils ist der Wertpapiernennbetrag maßgebend, bei Wertpapieren ohne Nennbetrag die Stückzahl" ("Para la tasación de las cuotas es decisivo el precio nominal de los títulos-valor; tratándose los títulos-valor sin precio nominal, [lo será] el número de piezas [unidades]"). Esto significa que, en realidad, debe hacerse un doble cálculo: de los títulos con y sin valor nominal. En el conjunto de los primeros, la cuota de un depositante corresponde a la proporción entre el valor nominal de todos los títulos y el valor nominal de los confiados por el depositante de que se trate. En el conjunto de los segundos, la cuota de un depositante corresponde a la proporción entre el total numérico de los títulos depositados y el total de los confiados por el depositante de que se trate. 
de valores será por menos; pero el depositario debe responderle de este perjuicio, a menos que la pérdida dependa de circunstancias que no le fueron imputable $(\operatorname{Depot} G$., $\S 7,2)$.

6. Durante la discusión a que dio lugar el proyecto de la futura ley $\mathrm{N}^{\circ} 18.876$ en las comisiones legislativas de la Junta de Gobierno que sesionaban para aprobarlo, el esquema alemán fue expresamente invocado, pero solo en lo concerniente al tipo que da origen a una comunidad sobre el fondo de todos los títulos fungibles depositados (Sammelverwahrung), sin alusión a las demás formas ${ }^{56}$. Pero fueran cuales hayan sido las opiniones particulares de algún participante en las correspondientes sesiones, la idea de que en el sistema de la ley $\mathrm{N}^{\circ} 18.876$ haya quedado establecida la idea de una comunidad por cuotas (o pro indiviso) sobre el conjunto de títulos depositados no es admisible ni puede sostenerse ${ }^{57}$, porque falta toda base legal para ello ${ }^{58}$.

También se insinuó en la misma sede que la atribución de dominio a la empresa depositaria sería una ficción legal ${ }^{59}$. Asimismo debe desecharse

${ }^{56}$ En la sesión de 23 de junio de 1989, se recordó por. Raúl Varela: "En algunos sistemas, como el alemán, los depositantes se convierten en codueños de la masa depositada. [...]. Pareciera que esto es lo que ocurre con los títulos al portador. Estos pierden su 96 individualidad cuando están en el depósito” (p. 6). Más adelante, en la sesión de 12 de julio de 1989, parece haber aludido a esta comunidad el Superintendente de Valores y Seguros, Fernando Alvarado, cuando expresó: “[...] en la relación depositante-depositario-empresa de depósito, el dominio [del valor] pertenece al depositante y debe estar contabilizado el valor como de dominio del depositante; no un título singular, sino que una cuota dentro del paquete de valores que tenga la empresa" (p. 24)

${ }^{57}$ En similar sentido MatTAR Oyarzún(1999), p. 184, aunque este autor solo considera "discutible" tal idea y no directamente inadmisible. Termina aceptando una comunidad de riesgos entre los depositantes, por la pérdida o el deterioro fortuitos de los valores depositados, ya que esa mengua la sufren todos los depositantes ("tenedores de valores", los llama). En todo caso, eso era así en el proyecto (art. 13), pero no en la ley, cuyo art. 28 inc. $2^{\circ}$ solo autoriza a disminuir el volumen de las operaciones proporcionalmente a la insuficiencia verificada. Por lo demás, el art. 27 carga a la empresa las mermas experimentadas por los títulos.

${ }^{58}$ Recuérdense las reglas sobre mezcla de materias áridas o líquidas que da el Código Civil, que, es cierto, dan lugar a una comunidad (art. 663 del CC); pero solo un derecho al valor por parte del interesado que tuvo conocimiento de lo que se hacía por otra persona (art. 666), así que el dicho interesado pierde el dominio y no hay comunidad, lo cual significa que no tiene dominio sobre cuota alguna. Como en todo depósito el depositante no puede menos que saber el destino de sus valores, la última disposición citada confirma que, en realidad, la operación destinada a confundir títulos homogéneos (si se la quiere asimilar a una mezcla de áridos o líquidos) no forma comunidad y que cada depositante deja de ser dueño de los valores que deposita.

${ }^{59}$ En la sesión de 2 de agosto de 1989, dijo Fernando Alvarado, Superintendente de Valores y Seguros, como remate de cierta explicación de por qué la empresa depositaria debía ser considerada como dueña: "Entonces se llega a esta ficción de que la custodia [es decir, la empresa depositaria] aparezca como dueña" (p. 14). 
esta posibilidad, para la cual la ley no ofrece asidero expreso alguno, en circunstancia de que una ficción legal (si es que existen) debe ser expresa y directamente establecida. Por su definición, una ficción consiste en dar por inexistente una realidad jurídica ${ }^{60}$ que existe o por existente otra que no existe. Ahora bien, si la atribución del dominio de los valores depositados a la empresa depositaria fuera una ficción, nada del sistema legal tendría que hacer pensar en tratarse eso de una realidad jurídica; pero el art. 3 de la ley $\mathrm{N}^{\circ} 18.876$ prescribe con toda claridad que la entrega llamada a perfeccionar el depósito se debe hacer mediante las formalidades propias de la transferencia de dominio (titularidad) de los valores a la empresa; y el art. 5 de la misma ley ordena considerar dueño de los valores recibidos a la empresa, al menos en relación con su emisor y terceros; así que no resulta tan ficticia la transferencia del dominio (titularidad) de aquellos a esta ${ }^{61}$.

\section{EJERCICIO DE LOS DERECHOS POLÍTICOS Y PATRIMONIALES}

QUE CONFIERE EL VALOR

Los valores suelen conferir ciertos derechos a su titular; y suele clasificárselos en políticos (terminología que solo aparece en el inc. $1^{\circ}$ del art. 5) y patrimoniales (así en los arts. 5 inc. 1 y 24 inc. $1^{\circ}$ ). Los primeros radican en poder participar en la adopción de decisiones con respecto al emisor del valor, como votar en las juntas de accionista de sociedades anónimas o en las juntas de tenedores de bonos y en otras asambleas semejantes, como dicen los arts. 12 y 24 . Los segundos consisten en la facultad de percibir prestaciones dinerarias conferidos a los titulares de valores y de aprovechar ciertos privilegios de contenido económico vinculados con ellos, como son los dividendos de las acciones, la recepción de acciones liberadas de pago ("crías") o la opción para suscribir nuevas acciones emitidas antes de ser ofrecidas en el mercado (cfr. con los arts. 12 inc. $4^{\circ}$ y 24 ).

a) Por lo que atañe a los derechos políticos, ellos permanecen en cabeza del depositante pese a haberlos transferido a la empresa depositaria para perfeccionar el depósito (art. 12 inc. $1^{\circ}$ de la ey $\left.\mathrm{N}^{\mathrm{o}} 18.876\right)^{62}$. Por consi-

${ }^{60}$ Difícilmente, pues, una ficción atañe a hechos naturales. Sobre el punto: LuNA SERrano (2013), No 32, pp. 78-83

${ }^{61}$ De otra opinión Mattar Oyarzún (1999), p. 184; pero sin fundamento, porque no lo es que la "[...] historia fidedigna [de la ley $\mathrm{N}^{\circ} 188.876$ ] plantea la forma de constituir el depósito como una ficción legal que no debe alterar la propiedad individual sobre determinada cantidad de valores depositados y registrados en cuentas electrónicas individuales [...]”. Homogéneo

${ }^{62} \mathrm{Al}$ efecto, la misma disposición y el inc. $2^{\circ}$ imponen a la empresa depositaria el deber de remitir al emisor una lista suscrita por su gerente o la persona que este designe de manera 
guiente, quien puede asistir a una junta de accionistas y votar en ella es el titular de la acción, aunque esté depositada, y no la empresa depositaria. Por lo demás, de acuerdo con lo dispuesto por el inc. $2^{\circ}$ del art. 24 de la ley $\mathrm{N}^{\circ} 18.876$ :

"Las empresas de depósito de valores no podrán concurrir a las juntas de accionistas, de tenedores de bonos o asambleas de aportantes, en representación de los depositantes o de los mandantes de éstos".

Esta disposición, añadida al texto original por el art. $11 \mathrm{~N}^{\circ} 4$ de la ley $\mathrm{N}^{\circ}$ 19.705 (DO. de 20 de diciembre de 2000), se refiere a los llamados derechos políticos, vale decir, a la asistencia a las juntas de accionistas, de tenedores de bonos y asambleas de aportantes (y, por ende, al voto en ellas). Como se aprecia, la norma inhabilita a las empresas de depósitos para asistir (y votar) en estas asambleas en representación de los depositantes, sean a nombre y por cuenta propios, sean por cuenta ajena.

b) En lo relativo a los derechos patrimoniales la ley dice que se empleará "el mismo sistema", queriendo decir que se aplicará las mismas reglas, esto es, también tales derechos permanecen radicados en cabeza del titular del valor depositado ${ }^{63}$. Pero, a diferencia de cuanto acaece con los derechos políticos, el art. 24 permite que los depositantes confieran mandato a las empresas de depósito para ejercer los derechos patrimoniales emanados de los valores que les entregaron:

"Las empresas podrán también con autorización expresa del depositante hacer efectivos los derechos patrimoniales que deriven de los valores recibidos en custodia, como concurrir a la suscripción y pago de valores de oferta pública por cuenta de éstos, cobrar y percibir amortizaciones, intereses, dividendos, repartos y otros beneficios a que tengan derecho los depositantes"

especial para cumplir tal función, en que se individualice a cada titular de valores, que lo sea a la fecha en que, de acuerdo con las reglas aplicables, tengan derecho a participar en la asamblea, se señale el número de unidades de valores que corresponda a cada titular y se indique los derechos reales, medidas precautorias y embargos que los afecten "con el detalle necesario para que se pueda determinar a quienes pertenece el derecho a voto". La lista debe ser remitida una vez cerrado el registro (de accionistas, de tenedores de bonos, etcétera) y antes de la celebración de la junta de que se trate y, en todo caso, antes de la calificación de poderes para participar en ella. Se observará que hay incongruencia en las normas: el inc. $1^{\circ}$ dice que la lista debe contener el nombre de los titulares de valores; pero el inc. $2^{\circ}$ habla de que la lista ha de individualizar a los depositantes. Ahora bien, "titular" y "depositante" de valores no son lo mismo, porque un depositante puede ser por cuenta ajena (v. el cap. VIII).

${ }^{63} \mathrm{Y}$ también la depositaria tiene el deber de remitir la lista de titulares al emisor, regulada por los incisos $1^{\circ}$ y $2^{\circ}$ del art. 12 . 
(en igual sentido el art. 16 del Regl. L. dep. val.) ${ }^{64}$. El art. 14 del Regl. L. dep. val. autoriza la existencia de cuentas dinerarias en la empresa a favor de los depositantes, donde acumular los cobros de derechos patrimoniales que en su nombre haga la empresa, si es que esta no fue autorizada para transferir el diario a cuentas corrientes bancarias.

c) Puede acaecer que el depositante no sea el titular de un valor, sino un tercero, por cuenta de quien actúa el depositante. El inciso final del art. 12 establece que, en tal caso, el derecho a voto y los derechos patrimoniales se ven regulados por las mismas reglas de los incisos anteriores. Eso significa que no es el depositante quien puede ejercer los derechos políticos y patrimoniales derivados del valor, sino aquel por cuenta de quien actúa el depositante. Aunque la ley no lo dé a entender, debe pensarse en que tal es así siempre que el depositante actúe a nombre propio y por cuenta ajena identificada ante la empresa depositaria; y en que no es así si el depositante actúa a nombre propio y por cuenta ajena no identificada, porque el emisor no tiene cómo saber quién había sido el titular de los valores para gestionar los cuales confirió mandato a un agente quien los depósito sin identificar a su mandante.

d) Es congruente, en consecuencia, que el art. 5 de la ley $\mathrm{N}^{\circ} 18.876$ declare que la empresa, pese a ser considerada, ante el emisor y terceros, dueña (o sea, titular) de los valores depositados, eso no significa que el depositante o su mandante, si es el caso, dejen de tener dominio de los valores depositados, mas solo "para el ejercicio de los derechos políticos y patrimoniales cuando corresponda".

\section{Transferencia QUe AFecte a los Valores ya Depositados}

Durante el depósito, puede acaecer que el depositante quiera transferir los valores que depositó. No podría proceder directamente a ello, porque con la entrega traslaticia, o tradición, que hizo de los valores para depositarlos, dejó de ser su dueño, el cual es ahora la empresa depositaria. De ejecutar su transferencia el depositante, esta sería a non domino. Lo que sí puede hacer sin obstáculo es ceder el crédito que tiene contra la empresa, sobre el tantumdem de títulos. Con ello, esta última queda obligada a restituirlo al cesionario. A la materia se refieren los arts. 7 y 8 de la ley $\mathrm{N}^{\circ} 18.876$, los cuales, aunque hablan de "transferencias de valores" no pueden, por lo dicho, sino que referirse a unas "transferencias de créditos".

${ }^{64}$ Con todo, según el art. 13 del Regl. L. dep. val., la empresa puede negarse a recibir en depósito valores respecto de los cuales sus titulares no hubieran ejercicio la totalidad de los derechos patrimoniales devengados en su favor. Se trata, pues, de evitar que haya situaciones pendientes, causas de eventuales de conflictos. 
Preliminarmente cabe advertir que las empresas de depósito no transfieren ellas mismas, pues como dice el art. 1, parte de su función solo es "facilitar las operaciones de transferencia".

Se distingue dos situaciones en la materia.

a) La primera es que la transferencia del crédito haya de tener lugar entre dos personas que actualmente sean depositantes de valores en una misma empresa y, por cierto, que la transferencia haya de afectar al todo o parte de los valores que habían sido depositados por el cedente. La transferencia o cesión del crédito es ejecutada merced:

i) a una comunicación, bien escrita en soporte material, bien por medios electrónicos, que -dice la ley- "los interesados entreguen a la empresa" y

ii) a un cargo o débito en la cuenta de quien transfiere y un abono o acreditación en la de quien adquiere (art. 7).

¿Cuál es el alcance de la frase transcrita entre comillas? El plural ("los interesados entreguen" ${ }^{65}$ ) insinúa que cada interesado deba entregar una comunicación por separado. Ahora bien, los "interesados" no pueden ser otros que el cedente y el cesionario; y, de esta manera, se trataría de una comunicación del primero a la empresa, para autorizarla a que proceda al cargo o débito de los valores de su cuenta; y otra del cesionario a la misma empresa, para comunicarle que debe proceder al abono o crédito de los mismos en la suya. Si no fuera así, habría que pensar en una única comunicación a la empresa; pero cंde quién: del cedente o del cesionario?66.

La ley añade que, para la empresa ("ante la empresa"), la comunicación (ahora habla en singular ${ }^{67}$ ) es título suficiente para "efectuar tal transferencia". Esta última alusión es, en realidad, al cargo y al abono que señala el art. 7, porque la voz 'transferencia', en la economía de ese artículo, designa al acto total integrado por las comunicaciones que deben entregarse a la empresa y el asiento del cargo y del abono por esta; así que las comunicaciones son parte de la transferencia.

No debe confundirse el "título" de que señala el art. 7 con el título de la cesión, que debe ser traslaticio de dominio, sea oneroso (compraventa, permuta, pago, crédito ${ }^{68}$ ), sea gratuito (donación, legado), para justificar

${ }^{65}$ Véase la n. 65.

${ }^{66}$ Por cierto, no hay obstáculo a que haya una única comunicación a la empresa, pero conjunta del cedente y del cesionario.

${ }^{67}$ Pero esta forma singular en oposición a la plural precedente no es argumento para apoyar la idea de que la comunicación deba ser una sola y única, porque la norma ahora habla en general y todavía puede entenderse una referencia a la comunicación del cedente y del cesionario.

${ }^{68}$ Sobre un contrato crediticio recayente sobre valores, véase GuZMán BRITO (2012), pp. 157-180. 
la cesión que, como se sabe no es más que una tradición, uno de cuyos requisitos es la presencia de un tal título (art. 675 del $C$ C). El "título" referido en el art. 7 reemplaza, ante la empresa, al título de cesión. Esto viene a significar que no es necesario dar a conocer a la empresa el título que realmente operó y justifica la cesión o tradición. A la empresa deben serle suficiente las comunicaciones establecidas en el art. 7.

b) Si el adquirente o cesionario de los títulos depositados no tiene cuenta de depósito en la empresa en que ellos están depositados, las operaciones de cargo y abono antes descritas no pueden ser ejecutadas, como es evidente. Para tal caso, el art. 8 de la ley $\mathrm{N}^{\circ} 18.876$ dispone que las transferencias hayan de ser efectuadas "mediante las formalidades propias de la transferencia del dominio, según sea la naturaleza del título de que se trate". Esta frase no puede dejar de significar que la transferencia deba hacerse mediante la entrega material del título si el valor es "al portador", merced a su endoso si es "a la orden" y como indica el art. 1901 del $C C$ (cfr. con el art. 162 del $C$ Com.) si es "nominativo". Pero es claro que el art. 8 no se puso en el caso de que el valor esté depositado por el cedente en una empresa de custodia, caso en el cual puede seguir siendo verdadero que el adquirente o cesionario de esos títulos no tenga cuenta de depósito en la empresa en que el cedente los había depositado. En tal caso, el cedente tendría que retirarlos de esta última para proceder a la operación de entrega, endoso o cesión de títulos nominativos depositados. Por tal razón la frase del art. 8: "con cargo a los valores disponibles que el depositante tenga en cuenta", carece de apoyo en la realidad. Tampoco lo tiene esta otra frase: "El depositante comunicará a la empresa por escrito o por vía electrónica el nombre del beneficiario"; ni, en fin, la siguiente: "Esta comunicación ante la empresa constituirá título suficiente para efectuar tal transferencia". Por supuesto, el cesionario no tiene por qué depositar en alguna empresa los títulos adquiridos.

Como consecuencia de todo lo anterior, la transferencia de valores en el caso en examen es completamente ordinaria.

XII. PURGa DE LA ADQUiSición DE LOS VALORES DEPOSITAdos Y ENAJENADOS Y RESPONSABILIDAD DEL ENAJENANTE Y LA EMPRESA FRENTE A TERCEROS

\section{Purga de los valores depositados y enajenados}

a) Puede acaecer que los valores que van a ser depositados estén afectos a "gravámenes, prohibiciones o embargos". Por lo primero se debe entender tanto a los derechos reales de usufructo, uso o prenda, únicos posible sobre valores como a la medida precautoria de retención (arts. 
$290 \mathrm{~N}^{\circ} 3$ y 295 del $C P C$.); bajo la voz 'prohibiciones' se comprende la medida precautoria de prohibición de celebrar actos o contratos (arts. $290 \mathrm{~N}^{\circ} 4$ y 296 del $C P C$.) y la cláusula de no enajenar, cuando esta es, sin discusión, valida ${ }^{69}$. La palabra 'embargo' envuelve toda y cualquier clase de embargo ejecutivo o precautorio que afecte a ciertos valores ${ }^{70}$. En el caso de los embargos, recuérdese que la enajenación de cosas (valores en este caso) embargadas por decreto judicial adolece de objeto ilícito, salvo que el juez la autorice o el acreedor la consienta (art. $1464 \mathrm{~N}^{\circ} 3$ del $C C$ ); con respecto a cosas que son materia del juicio, si el tribunal decreta prohibición de celebrar actos o contratos (art. 296 inc. $2^{\circ}$ del $C P C$ ) las afecta el $\mathrm{N}^{\circ} 4$ del art. 1464 del $C C$.

Por el hecho de ser depositados unos valores afectos gravámenes, prohibiciones o embargos, estas limitaciones, por cierto, no caducan. Por lo demás, puesto que el depósito de valores transfiere su dominio a la empresa depositaria, el acto viola algunas de aquellas, en el caso de consistir en la medida precautoria de retención o de prohibición de celebrar actos o contratos. Si solo hay derecho reales que afecten a los valores, su transferencia es con tales derechos, según las reglas generales

b) Ahora bien, el art. 15 de la ley $\mathrm{N}^{\circ} 18.876$ expresa que los valores adquiridos mediante cualquiera de los sistemas de transferencia estableci102 dos en ella misma se entenderán libres de "gravámenes, prohibiciones o embargos". El efecto se produce tanto en favor de la empresa de custodia, cuando adquiere los valores por la tradición que perfecciona su depósito en ella misma, como en favor de terceros, que los adquieren con posterioridad al depósito. El art. 15, en efecto, no distingue, pues, dice: "Los valores adquiridos mediante cualquiera de los sistemas de transferencia establecidos en esta ley, se entenderán libres [...]”. Por consiguiente, la transferencia de valores, bien al ser depositados (porque el depósito es una transferencia), bien de los ya depositados, los purga de los eventuales gravámenes, prohibiciones o embargos que los afectaban antes de la transferencia, de manera que se los adquiere libre de ellos por quien corresponda. Supóngase constituida una prenda sin desplazamiento por deuda ajena sobre ciertos valores, que después son depositados por su titular (el constituyente de la prenda) en una empresa del género y posteriormente enajenados por el mismo. El adquirente se hace titular de los valores, pero libres o purgados de la prenda; vale decir, esta no puede ser perseguida ni ejecutada por el acreedor prendario contra el nuevo titular.

${ }^{69}$ Véanse los arts. 751,793 inc. $3^{\circ}$ y $1432 \mathrm{~N}^{\circ} 1$ del $C C$. Fuere excesivo entrar en el debatido y fatigado tema de la validez y los efectos de la cláusula de no enajenar.

${ }^{70} \mathrm{Si}$ no se aceptare que la medida precautoria de retención caiga bajo la voz 'gravamen', no debería caber duda que sí cae bajo la palabra 'embargo'. 
c) Si el enajenante incurrió en alguna infracción al intervenir en la configuración de las hipótesis de purga ${ }^{71}$, puede ser sancionado por la Superintendencia de Valores y Seguros en conformidad con su ley orgánica (art. 15 inciso final).

d) El adquirente de los valores puede convenir con su enajenante en que subsistan los gravámenes, prohibiciones o embargos purgables, renunciando así a la purga. En tal caso, tales valores deben ser registrados en la cuenta del adquirente (si este quiere mantener el depósito, por cierto), pero en ítem separado con respecto a los demás que él tenga y no se considerarán homogéneos con respeto de los que sean del mismo tipo, especie, clase, serie y emisor cuyo titular sea ese depositante (art. 15 inc. 3 y 4 inc. $\left.2^{\circ}\right)^{72}$.

\section{Responsabilidad del enajenante de los valores purgados}

Esta purga concerniente a gravámenes, prohibiciones o embargos que hayan afectado a los valores depositados y enajenados es sin perjuicio de la responsabilidad que pueda soportar el transferente de los mismos ante su adquirente ${ }^{73}$, si es que los valores realmente estaban afectados por gravámenes, prohibiciones o embargos oponibles al transferente (art. 15 inc. $1^{\circ}$ ). En el ejemplo ofrecido, la prenda era oponible al transferente por el acreedor prendario, por cuya enajenación aquel vio frustrada la garantía. Si dicho acreedor sufrió algún perjuicio, por ejemplo, si la deuda que había sido garantizada por la prenda no fue pagada por su deudor, entonces tiene acción contra el constituyente-transferente para exigirle la indemnización del perjuicio sufrido.

\section{Responsabilidad de la empresa en que estaban depositados los valores purgados}

También la empresa puede tener que responder de los perjuicios de terceros derivados de la purga (art. 15 inc. $\left.1^{\circ}\right)^{74}$.

a) Para continuar con el ejemplo antes ofrecido, supóngase que la empresa omitió registrar la circunstancia de que los valores que recibía

${ }^{71}$ La ley se limita a decir "que hubieren incurrido en las infracciones a que se refiere este artículo", el cual no tipifica ninguna infracción; pero es claro que se refiere a posibles infracciones cometidas en las hipótesis de purga.

${ }^{72} \mathrm{El}$ inc $3^{\circ}$ del art. 15 hace esta prevención: "Lo dicho en los incisos anteriores no obsta a lo dispuesto en el inciso segundo del artículo 6"; y no se acierta a entender el sentido de esa remisión.

${ }^{73}$ Estas cuestiones sobre responsabilidad civil deben tramitarse según las normas del juicio sumario y entonces cesa la posibilidad de aplicar el art. 681 del $C P C$.

${ }^{74}$ Véase la n. 71. 
en depósito estaban previamente pignorados, lo que pudo haber hecho merced a la consulta del Registro de Prendas sin Desplazamiento que lleva el Servicio de Registro Civil e Identificación. Aunque haya sido así, la enajenación de los valores pignorados los libera o purga de la prenda, de modo que el acreedor prendario no la puede ejecutar o perseguir; pero está en condiciones de exigir a la empresa responderle por el perjuicio que haya sufrido.

b) La responsabilidad de la empresa por los perjuicios derivados de la purga es objetiva (art. 15 inc. $2^{\circ}$ ). Esto significa que es suficiente la prueba del perjuicio sufrido y de la atribuibilidad material de este a la empresa, sin necesidad de haber de demostrarse haber ella obrado con culpa o dolo. Significa, además, que el caso fortuito o la fuerza mayor que incidieron en el resultado no la liberan de responder.

c) La indemnización a que haya de ser condenada la empresa queda limitada al precio promedio ponderado, en los treinta días precedentes al de la transferencia, de valores del mismo tipo, especie, clase serie y emisor de los enajenados (art. 15 inc. $2^{\circ}$ ). Con dos excepciones, empero:

i) si se prueba perjuicios directos por mayor valor al resultante del antedicho cálculo (art. 15 inc. $2^{\circ}$ ), caso en el cual se entiende que la condena debe asumir ese valor y

104 ii) si el gravamen, prohibición o embargo purgados protegían un crédito o derecho personal de monto menor al monto resultante del cálculo según la regla general, caso en el cual la indemnización se reducirá a ese monto menor.

d) Si la empresa cometió alguna infracción al intervenir en la configuración de las hipótesis de purga ${ }^{75}$, puede ser sancionada por la Superintendencia de Valores y Seguros en conformidad con su ley orgánica (art. 15 inciso final).

\section{Derechos ReAles Que afeCten a los VAlORES Depositados}

El art. 14 de la ley $\mathrm{N}^{\circ} 18.876$ regula el tema de la constitución de derechos reales concernientes a los valores depositados. El inc. $1^{\circ}$ ofrece la regla general:

"El depositante puede constituir prendas y derechos reales sobre los valores que tenga depositados en los mismos casos en que podría hacerlo si no estuvieran en depósito”.

${ }^{75}$ La ley se limita a decir "que hubieren incurrido en las infracciones a que se refiere este artículo", el cual no tipifica ninguna infracción; pero es claro que se refiere a posibles infracciones cometidas en las hipótesis de purga. 
1. Preliminarmente se deben examinar algunos puntos generales que ofrece la norma.

a) Esta habla de "prendas y derechos reales", en circunstancias de que la prenda es ella misma uno de los derechos reales posibles (art. 577 inc. $2^{\circ}$ del $C C$ ), así que el segundo extremo mencionado comprende al primero y la mención de la prenda es superflua.

b) Pero los valores no admiten toda clase de derechos reales. Como aquellos son muebles, quedan excluidos los que necesariamente han de recaer sobre inmuebles, es decir, los derechos reales de habitación, servidumbres, hipoteca y censo. Por la especialidad de sus objetos, los derechos mineros, de aprovechamiento de aguas, moral y patrimonial de autor y los industriales tampoco son posibles sobre los valores. En tales circunstancias no restan más que los derechos reales generales posibles sobre muebles, como son los de usufructo, uso y prenda; con todo, acerca del segundo puede discutirse en que habría de consistir aplicado a los valores.

c) La norma en examen legitima al depositante para constituir derechos reales sobre los valores depositados (art. 14 inc. $1^{\circ}$ ). Pero resulta que este, según la ley (art. 5), no es dueño de tales valores ante terceros $\mathrm{y}$, dogmáticamente, tampoco ante la empresa depositaria (v. el cap. IX), así que los derechos reales de que se trata serían constituidos a non domino.

Esta consecuencia indeseable queda superada cuando se reconoce que el depositante es titular de un crédito o derecho personal contra la empresa depositante cuyo objeto son los valores depositados, de modo de estar está en condiciones de constituir derechos reales sobre ese crédito -que es mueble- por lo cual, en realidad, se trata del usufructo, de la prenda y del uso sobre el derecho personal o crédito a los valores ${ }^{76}$.

2. El segmento primero del art. 5 inc. $2^{\circ}$ concede legitimación al depositante para la constitución de prendas (mentadas bajo la expresión “otras limitaciones al dominio") en garantía de obligaciones personales ${ }^{77}$ suyas, si estuvieren identificados como pertenecientes a él en la cuenta de la empresa; y nosotros interpretamos que tales derechos han de recaer, en realidad, sobre su crédito a los valores depositados y no sobre los valores mismos. Si es así, aunque el inciso en comento no existiera la conclusión hubiera de ser que solo el depositante, en cuanto acreedor del crédito adquirido contra la empresa merced al depósito de sus valores en ella, está legitimado para la constitución de los derechos reales de que hablamos.

${ }^{76}$ Sobre la primera figura, véase GUZMÁn BRITO (2015a), pp. 61-85. Sobre la segunda: GuZmán Brito (2011a), pp. 9-44; GuZmán Brito (2011b), pp. 545-576.

${ }^{77}$ Véase la n. 86. 
Si los valores hubieran sido depositados en nombre propio y por cuenta ajena con identificación del mandante, las prendas que haya de afectarlos solo pueden ser constituidas para garantizar obligaciones de ese mandante (art. 5 inc. $2^{\circ}$ segmento tercero).

Si los valores hubieran sido depositados en nombre propio y por cuenta ajena sin identificación del mandante, el segmento tercero de la misma norma ordena que la prenda solo pueda ser constituida por obligaciones de las personas que consten en el registro que el mandatario debe llevar de acuerdo con el art. 179 de la ley $\mathrm{N}^{\circ} 18.045$, el cual carga a los agentes de valores, corredores de bolsa, bolsas de valores, bancos o cualquier otra entidad legalmente autorizada, que mantengan valores por cuenta de terceros, pero a nombre propio, con el deber de inscribir en un registro especial y anotar por separado en su contabilidad estos valores con la individualización completa de la o las personas por cuenta de quien los mantiene [véase $\mathrm{v}, 2, a)]^{78}$.

3. En cuanto al procedimiento de la constitución, hay varias normas aplicables:

i) A solicitud del depositante, la empresa depositaria debe extender un certificado ${ }^{79}$-suscrito por el gerente la empresa o por la persona que este designe especialmente al efecto, y con indicación de la fecha y hora de su otorgamiento - y entregarlo al depositante, en que consten la cantidad de los valores depositados -que puede ser la total o limitada a una parte de ella, si lo pide, el depositante-, su tipo, clase, especie y calidad, lo mismo que el emisor de los valores y la individualización de $\operatorname{estos}^{80}\left(\right.$ arts. 14 inc. $2^{\circ}$ en relación con 13 de la ley $\mathrm{N}^{\circ} 18.876$ );

${ }^{78} \mathrm{El}$ segmento primero del inc. $2^{\circ}$ del art. 5 incluye a las prendas; pero el segmento segundo habla de "las resoluciones antes indicadas" (con referencia a embargos y medidas prejudiciales y precautorias, pero con olvido de las "otras limitaciones al dominio" entre las cuales están las prendas) y el tercero, de "tales embargos o medidas". Pero una correcta interpretación conduce a referir los últimos dos casos tratados también a las prendas.

${ }^{79}$ Este certificado es nominativo, intransferible y no negociable (art. 13 de la ley $\mathrm{N}^{\mathrm{o}}$ 18.876) y tienen mérito ejecutivo en contra de los emisores de los títulos certificados y demás personas obligadas a su pago; para el efecto de demandar el cobro, reemplazan a los títulos mismos (art. 14 bis 13 de la ley $\mathrm{N}^{\circ}$ 18.876).

${ }^{80} \mathrm{El}$ art. 13 inc. $1^{\circ}$ había dicho que en el certificado deben constar el tipo, la clase, la especie, la calidad y el emisor" de los valores; y en el inc. $2^{\circ}$ añade que el certificado debe "individualizar los valores de que se trate" ¿Cuál es el alcance de esta individualización a la luz de las menciones precedentemente señaladas? No se ve a qué otra mención se referiría el inc. $2^{\circ}$ que no fuera a la serie y al número de cada valor. Obsérvese que la norma, añade la "calidad" a la sucesión de conceptos que había venido usando (tipo, especie, clase, serie, emisor), aunque ahora omite el de "serie". 
ii) Para los efectos de la constitución del derecho real, el certificado así otorgado sustituye, por mandato legal, a los títulos representativos del valor de que se trate (art. 14 inc. $4^{\circ}$ de la ley $\mathrm{N}^{\circ} 18.876$ );

iii) Un notario público debe notificar a la empresa depositaria el hecho de la constitución del derecho real. Sin esta notificación, la constitución no es oponible a la empresa ni a terceros (art. 14 inc. $5^{\circ}$ de la ley $\mathrm{N}^{\circ}$ 18.876). Si la constitución tiene lugar entre depositantes de la misma empresa, las comunicaciones electrónicas simultáneas entre las partes y la empresa son suficientes para entender notificado el hecho de la constitución a la empresa (art. 14 inc. $6^{\circ}$ de la ley $\mathrm{N}^{\circ} 18.876$ );

iv) Recuérdese que los valores que hayan sido gravados con derechos reales deben ser registrados en ítems separados en la cuenta del depositante y que dejan de ser considerados como homogéneos respecto de los demás de su mismo tipo, especie, clase, serie y emisor (art. 4 inc. $2^{\circ}$ );

v) Cualquier interesado puede pedir a la depositaria certificar los títulos depositados y sus titulares, que estén gravados con derechos reales, cuáles y su fecha de constitución.

\section{RESTITUCIÓN DE LOS VALORES DEPOSITADOS}

1. El contrato de depósito ordinario impone al depositario la obligación de restituir la misma especie depositada al depositante (art. 2228 del CC) cuando este se la pida (arts. 2215 y 2226 inc. $1^{\circ}$ del $C C$ ). Pero cuando lo depositado son valores en una empresa de custodia, la obligación restitutoria de esta no es de los mismos valores individuales confiados, sino de otro tanto del mismo género de valores depositados, igual que en el depósito de dinero (art. 2221 del CC) o de otros fungibles, llamado tradicionalmente irregular. Es decir, la empresa depositaria debe entregar en devolución al depositante una cantidad de valores homogéneos igual a la recibida. Sigue en vigencia la regla civil de que la restitución es a voluntad del depositante (arts. 2215 y 2226 inc. $1^{\circ}$ del $C C$ ), al cual basta con dar una de retiro escrita o electrónica, según señale el reglamento interno, a la depositaria (art. 19 del Regl. L. dep. val.).

2. Sobre esta trata el art. 6 de la ley $\mathrm{N}^{\circ} 18.876$. En su segmento primero establece:

"La empresa cumplirá su obligación de restitución entregando valores homogéneos, al depositante o a quien éste le indique por los medios escritos o electrónicos que señale el reglamento interno”. 
Como se ve, la disposición contiene tres ideas:

i) Se cumple con la restitución merced a la entrega que la empresa hace de valores homogéneos a los recibidos originalmente por ella. Se recordará que la ley entiende por tales a los que sean idénticos en cuanto al tipo (de valor: si sean acciones, o cuotas de inversión, o bonos, etcétera), especie, clase, serie y emisor (art. 4 inc. $1^{\circ}$ segmento segundo). No está obligada, pues, a entregar los mismos valores recibidos;

ii) La entrega debe hacerse en primer lugar al depositante;

iii) La entrega puede hacerse, subsidiariamente, a un tercero indicado por el depositante por los medios escritos o electrónicos que señale el reglamento interno ${ }^{81}$.

Añade el segmento segundo del art. 6 en comento:

"La restitución se hará mediante las formalidades propias de la transferencia del dominio, según sea la naturaleza del valor que se restituya".

Como el depósito se constituye por la transferencia de los valores a la empresa (art. 3 inc. $1^{\circ}$ ), es congruente que la restitución de valores homogéneos 108 al depositante, o a quien este indique, deba hacerse por una transferencia también. Esta transferencia ha de tener lugar según la naturaleza del valor que se restituya; vale decir, si el valor es "al portador", la restitucióntransferencia debe hacerse mediante la entrega material del título; si es "a la orden", merced a su endoso (seguido de la entrega material); y si es nominativo, como indica el art. 1901 del $C C$ (cfr. con el art. 162 del $C C o m)^{82}$.

Cuando lo que se trata de restituir son acciones de sociedades anónimas o, bien, cuotas de fondos de inversión y los registros de accionistas o de aportantes sean administrados por la empresa depositaria o por una filial suya constituida de acuerdo con el art. 23 de la ley $\mathrm{N}^{\circ} 18.876$, el inc. $2^{\circ}$ del art. 6 en examen establece una regla especial ("no obstante lo anterior"), pues entonces, para ejecutar la restitución son suficientes las anotaciones (de descargo o debitación)

"simultáneas que haga la empresa o su filial, tanto en la cuenta que corresponda de las que mantenga el depositante, como en el registro del emisor respectivo".

${ }^{81}$ Obsérvese que la frase "por los medios-interno" se refiere a la indicación de a quién restituir los valores que puede hacer el depositante; no, pues, a la entrega de los valores; esta se hace como se indica acto seguido.

${ }^{82}$ En general, véase el título $4^{\circ}$ del libro II del CCom. (art. 162-165). 
El lenguaje de la ley es claro en orden a deber interpretarse esta regla como constitutiva de una transferencia especial. Dice que "bastará para efectuar la restitución": como esta consiste en una transferencia, aquello significa que para efectuar la transferencia bastarán las anotaciones simultáneas prescritas enseguida.

Si los valores que deberían ser restituidos se encuentran afectos a embargos, medidas precautorias o derechos reales (usufructo, uso o prenda), la empresa debe abstenerse de proceder a la restitución sin la autorización escrita de la persona en cuyo favor están establecidos o del juez en subsidio. Por lo que atañe al embargo, esta regla ha sido establecida en obsequio al art. 1464 del $C C$, según el cual hay objeto ilícito en la enajenación de cosas embargadas por decreto judicial, a menos que el juez lo autorice o el acreedor consienta en ello. Lo propio vale para la medida precautoria de prohibición de celebrar acto y contratos que recayó sobre los valores depositados que son materias de un juicio, cuya enajenación también constituye objeto ilícito según el $\mathrm{N}^{\circ} 4$ del art. 1464 (véase el art. 296 inc. $2^{\circ}$ del $C P C$ ). La aplicación del precepto al caso de los valores sujetos a derechos reales es de más difícil justificación, porque un usufructuario puede ceder su derecho de tal sin permiso del propietario (art. 793 inc. $1^{\circ}$ del $C C$ ) y lo propio acaece para el pignoratario en la prenda con o sin desplazamiento (art. 2404 del $C$ C), de modo las norma carece de razón a su respecto.

3. La empresa no está asistida por ningún derecho de retención, que la excuse de tener que restituir los valores al depositario (art. $2234 \mathrm{del} C C)^{83}$.

\section{Responsabilidad DE LA EMPRESA DEPOSITANTE}

Por Derecho Común, un depositario generalmente responde de la culpa grave (art. 2222 inc. $2^{\circ}$ del $C$ C) y, por cierto, del dolo. En ciertos casos su responsabilidad llega a la culpa leve (art. 2222 inc. $3^{\circ}$ ); y las partes pueden estipular que responda de toda clase de culpa (art. 2222 inc. $1^{\circ}$ del $C C$ ). La ley $\mathrm{N}^{\circ} 18.876$ modifica estas reglas y establece que la empresa haya de responder de la culpa levísima (art. 27). Esta su responsabilidad cubre de manera especial:

${ }^{83} \mathrm{El}$ art. 2234 del $C C$ contiene una excepción descrita en el que le sigue; pues el depositario puede retener la cosa depositada como seguridad del pago, por el depositante, de la indemnización de ciertas expensas de conservación y de los perjuicios que, sin su culpa, le hubiere ocasionado el depósito. Pero no creemos aplicables estas excepciones al depósito de valores, atendida su onerosidad. El precio de este contrato debe cubrir las expensas de conservación y los eventuales perjuicios que sufra el depositario; son, pues, riesgos de su profesión. 
i) cualquier merma, extravío, perdida, deterioro o destrucción que experimenten los valores entregados en depósito;

ii) cualquier retardo en la restitución de esos valores;

iii) los errores o retardos que se registren en los servicios de transferencia de valores y liquidación de operaciones, de los que se deriven perjuicios para los depositantes;

iv) la autenticidad e integridad de los valores que haya admitido en custodia (art. 27).

De acuerdo con las reglas generales, la empresa debe indemnizar al depositante perjudicado por los actos de que responde. Si se trata de mermas de valores sufridas por los depositantes, la indemnización es una reparación, pues consiste en una reposición, a expensas de la empresa, de la totalidad de las mermas sufridas a cada uno, y debe proceder a ello tan pronto como se detecten o reclamen, vale decir, sin previa sentencia judicial (art. 27 inc. $1^{\circ}$ inc. $2^{\circ}$ ). Con esta regla tiene relación el art. 28 incisos $2^{\circ}$ y $3^{\circ}$. El primero atañe al caso de que se verificare la existencia de un superávit o sobrante de algún valor o un déficit o falta en el fondo de valores, y establece que no por ello se interrumpirán -dicho así en general- las operaciones de la empresa. El inc. $3^{\circ}$ añade:

"Las empresas deberán velar porque las situaciones de diferencia [o sea, de superávit y de déficit] expuestas en el inciso anterior no sucedan y en todo caso, determinar dentro de las cuarenta y ocho horas siguientes a la detección, el monto de la diferencia y sus causas, los valores y depositantes afectados y las medidas adoptadas para superar las diferencias; pudiendo hacerse en todo caso, efectiva la responsabilidad de la empresa por los perjuicios que estas situaciones hubieren ocasionado a los depositantes. En el mismo plazo deberá comunicar los hechos al comité de vigilancia y a la Superintendencia”.

La norma, pues, impone una obligación especial a la empresa, consistente en velar para que no se produzcan sobrantes ni faltas de valores en el fondo depositado; y le concede un plazo de cuarenta y ocho horas, contadas desde la verificación de la diferencia, para determinar su monto concreto, las causas de la diferencia y los valores y depositantes afectados y para disponer las medidas destinadas a superar la diferencia ${ }^{84}$; añade que "en todo caso" se puede hacer efectiva la responsabilidad de la empresa por

${ }^{84}$ Carece de mucho sentido que el plazo de cuarenta y ocho horas sea para, entre otras, "determinar las medidas adoptadas para superar las diferencias", como dice la norma. Adquiere pleno sentido cuando interpretamos que el plazo es para adoptar medidas. 
los perjuicios que las diferencias (especialmente los déficit) hubieran ocasionado a los depositantes. Esa responsabilidad se manifiesta en su tener que efectuar la reposición, a expensas de la empresa, de la totalidad de las mermas sufridas a cada depositante, tan pronto como se verifiquen o reclamen, vale decir, sin previa sentencia judicial.

Sin perjuicio de todo esto, queda a salvo el derecho de la empresa para repetir contra el depositante que haya incurrido en la acción u omisión dañosa ${ }^{85}$ o sea responsable por ella (art. 27 , inc. $1^{\circ}$, segmento segundo, parte final $\left.{ }^{86}\right)$.

En todo caso, la empresa que no ha incurrido en mora de restituir los valores al depositario, no responde del caso fortuito o fuerza mayor que los haya deteriorado o destruido, según las reglas generales (art. $2230 \mathrm{del}$ $C C$ ); salvo que la afecte una responsabilidad objetiva, como acaece en el caso de purga (art. 15 inc. $2^{\circ}$; v. el cap. XII, 3).

\section{Deudas de las empresas DEPOSITARIAS Y PROCESOS DE REORGANIZACIÓN Y LIQUIDACIÓN QUE LAS AFECTEN}

1. La ley $\mathrm{N}^{\circ} 18.876$ establece algunas normas sobre la hasta no hace mucho tiempo llamada quiebra (y hoy reorganización y liquidación) de las empresas de depósito, que no nos incumben atendido su carácter procedimental. En este trabajo, el punto que interesa es el siguiente: si la falencia de una de tales empresas afecta a los valores depositados. De atenerse al hecho de que tales valores pertenecen a la empresa, incluso, aunque se limite tal pertenencia solo frente a los terceros, como hace

${ }^{85}$ La norma da a entender que la repetición es solo con respecto a las situaciones descritas en el art. 27, que poco antes se distribuyeron en cuatro grupos; y no por daños provenientes de acciones u omisiones que no estén descritas ahí. El asunto carece de interés práctico, porque las descripciones contenidas en el art. 27 son muy exhaustivas y difícilmente se hallará alguna que no esté contenida en él.

${ }^{86}$ La parte citada dice: "todo lo anterior, sin perjuicio de su derecho de repetir contra el depositante que haya incurrido o sea responsable por acción u omisión de las situaciones descritas en este artículo". La frase no está arreglada: se trata del "depositante que haya incurrido" y del "depositante que sea responsable"; pero al intentar las conexiones con lo que sigue, aunque resulta bien "depositante que sea responsable por acción u omisión de las situaciones descritas en este artículo", "depositante que haya incurrido" se queda sin complemento: incurrido, ¿̇en qué? Es evidente que la frase está incompleta. Pero también parece claro que se trata del depositante que haya incurrido en las situaciones descritas en este artículo y del "depositante que sea responsable por acción u omisión de las situaciones descritas en este artículo". 
el art. 5, como entre ellos se encuentran sus acreedores ${ }^{87}$, la conclusión lógica fuere que un proceso de reorganización y liquidación que afectare a la empresa tendría que cubrir los valores depositados en ella. Pero la ley optó por contradecir esta lógica, en función de inspirar confianza a los titulares de valores y de hacer entrar en los usos y costumbres la práctica de depositarlos en las empresas tipificadas por la ley $\mathrm{N}^{\circ} 18.876$, de modo que no fracasara la innovación que introdujo por el temor de los inversionistas en que sus valores quedasen sujetos al llamado derecho de prenda general de los acreedores (de la depositaria). En síntesis, pues, los acreedores de la empresa no tienen acción sobre los valores depositados en ellas y su llamado derecho de prenda general no los cubre.

2. Varias normas de la ley se ocupan en perfilar este régimen.

a) $\mathrm{El}$ art. 18 letra d) establece:

"Las empresas estarán sujetas a las siguientes reglas específicas:/ [...] d) Las operaciones relativas al patrimonio de la empresa serán totalmente independientes de las del conjunto de valores recibidos en depósito, y se contabilizarán separadamente de las de éste”.

b) $\mathrm{Su}$ art. $19^{\circ}$ dispone:

"Las empresas de depósito pueden poseer por cuenta propia valores de oferta pública. Estas empresas deben tener en su contabilidad debidamente individualizados por su número los títulos representativos de las cantidades de valores recibidos en depósito, de manera de distinguirlos de los títulos representativos de valores que posean por cuenta propia”.

c) El primer segmento del art. 5 inc. $2^{\circ}$ prescribe:

"Los valores que se encuentren depositados en la empresa, sólo podrán ser objeto de embargos, medidas prejudiciales o precautorias u otras limitaciones al dominio por obligaciones personales del depositante, cuando fueren de su propiedad y así lo identificare la cuenta respectiva".

${ }^{87}$ Podrá parecer extraño calificar de "terceros" a los acreedores de la empresa; pero es así en la concepción del art. 5 cuando examina los hechos desde el punto de vista del binomio depositante-empresa. La disposición dice que, en las relaciones entre la empresa y el depositante, este es el propietario de los valores; y que, ante el emisor de los valores y terceros, la empresa es considerada su dueña. En este contexto, pues, los acreedores de la empresa son claramente terceros. 
La norma limita, pues, la posibilidad de que los valores depositados puedan ser objetos de embargos, medidas prejudiciales o precautorias u otras limitaciones al dominio (como incautaciones en un proceso de liquidación) solo a la reclamación y ejecución de obligaciones ${ }^{88}$ del depositante identificado como titular de los valores en la respectiva cuenta de depósito (depositados, por ende, a nombre y por cuenta de aquél $)^{89}$; lo cual implica la exclusión de las mencionadas operaciones ejecutivas y cautelares cuando se trata de obligaciones de la empresa depositaria misma. Esto no es una mera inferencia a contrario, porque, además, está expresamente dicho por el segmento primero del art. 17 de la ley $\mathrm{N}^{\circ} 18.876$ :

"En los juicios en que se persiga la responsabilidad de una empresa o la ejecución forzada de sus obligaciones con terceros o con depositantes no se podrá, en caso alguno, decretar embargos, medidas prejudiciales o precautorias u otras limitaciones al dominio respecto de los valores que le hubieren sido entregados en depósito".

d) Si los valores habían sido depositados a nombre propio más por cuenta ajena, o sea, por cuenta de un mandante identificado frente a la empresa, las operaciones ejecutivas y cautelares que aquí se tratan solo podrán ser emitidas con respecto a obligaciones del mandante (art. 5 inc. $2^{\circ}$ segmento segundo ${ }^{90} \mathrm{y}$ art. 17 segmento segundo).

e) Cuando, en fin, los valores fueron depositados a nombre propio, mas por cuenta de mandantes no identificados frente a la empresa, el segmento tercero del art. 5 y el tercero del 17 ordenan que las

${ }^{88}$ La norma dice "obligaciones personales" lo cual no es una redundancia o un error, pues se trata de excluir las deudas de un mandante del depositante o de un representado suyo (caso es en los cuales, en efecto, ya no son obligaciones personales del depositante).

${ }^{89} \mathrm{El}$ segmento segundo del art. 17 de la ley $\mathrm{N}^{\mathrm{O}} 18.876$ reitera que podrá decretarse embargos, medidas prejudiciales o precautorias u otras limitaciones al dominio, respecto de los valores depositados "cuando se trate de obligaciones personales de los depositantes de los valores correspondientes"; pero añade que ello será "solamente hasta por el total que éstos [los depositantes] mantengan en la empresa", aunque esta añadidura es completamente innecesaria, porque a nadie se le podría ocurrir que las operaciones ejecutivas y cautelares de que trata la norma pudieran abarcar más que el total de los valores depositados por el depositante que las sufra. El segmento tercero del mismo artículo reitera la idea que poco antes había manifestado: "Sin perjuicio de lo anterior, podrán decretarse tales medidas, de conformidad a las reglas generales, por obligaciones personales de los depositantes respecto de los valores de su propiedad que mantengan en la empresa".

90 "Si los valores se encontraren depositados por encargo de terceros en cuentas que identifiquen el nombre del mandante, sólo podrán ser objeto de las resoluciones antes indicadas por obligaciones contraídas por los señalados mandantes". 
operaciones ejecutivas y cautelares en comento solo puedan ejecutarse en relación con obligaciones de las personas que aparezcan registradas como ordena el art. 179 inc. $1^{\circ}$ de la ley $\mathrm{N}^{\mathrm{o}}$ 18.045: "De mercado de valores" corredores de bolsa, bolsas de valores, bancos o cualquier otra entidad legalmente autorizada, que mantengan valores por cuenta de terceros, pero a nombre propio, a inscribir en un registro especial y anotar de manera separada en su contabilidad estos valores con la individualización completa de la o las personas por cuenta de quien los mantiene [véase $\mathrm{v}, 2, a)$ ].

\section{EXTINCIÓN DEL DEPÓSITO}

La doctrina de la extinción del contrato de depósito de valores debe tener necesariamente en cuenta que ese contrato es real; por consiguiente, varias de las causas generales de extinción de los contratos no pueden operar mientras no sea ejecutado el acto contrario al que lo perfecciona, vale decir, la devolución real de los valores; como se verá en cada caso.

\section{Retiro de los valores}

Si el depositante retira los valores depositados en la empresa eso extingue el contrato, sin perjuicio de las responsabilidades pendientes que eventualmente haya. Obsérvese que el hecho extintor es el retiro de los valores, no la petición de su retiro.

\section{Consignación de los valores.}

Si la empresa depositaria, de acuerdo con las reglas generales, consigna los valores que el depositante no quiso retirar, cuando debía, ese acto pone fin al contrato de depósito, sin perjuicio de las responsabilidades que se encuentren pendientes.

\section{Enajenación de los valores}

Si el legitimado para ello enajena los valores que estaban depositados (su crédito a ellos), con independencia de que el adquirente los retire o

${ }^{91}$ Ley $\mathrm{N}^{\mathrm{o}} 18.876$, art. 5 segmento tercero: “Tratándose de valores depositados por el depositante a nombre propio, pero por cuenta de terceros no identificados frente a la empresa, tales embargos o medidas sólo podrán hacerse efectivas en el registro que dicho depositante lleve de conformidad al artículo 179 de la ley $N^{\circ}$ 18.045, de Mercado de Valores". 
los deje en depósito a su vez, se extingue el contrato entre la empresa y el depositante que enajenó, sin perjuicio de las responsabilidades que queden pendientes entre ellos. Por supuesto, la extinción puede ser total o parcial, según que la enajenación haya sido con respecto a todos los valores depositados o a una parte de ellos.

\section{Prescripción extintiva}

La obligación de restituir los valores al depositante puede verse afectada por la prescripción extintiva en favor de la depositaria, cuando, durante el tiempo legal, el depositante o sus herederos no han ejercido la acción destinada a conseguir la restitución de los valores homogéneos o fungibles con los depositados originalmente; una vez declarada ella, el contrato de depósito mismo queda extinguido.

\section{No son causas de extinción aplicables al depósito de valores las siguientes}

\section{a) Plazo}

El contrato de depósito de valores de oferta pública, como se analizó (v. el cap. v), puede contener un plazo, aun indefinido (que obliga al depositario mas no al depositante). Pero su cumplimiento no extingue de inmediato el contrato, y solo autoriza a la empresa depositaria para exigir el retiro de los títulos por el depositante (art. 2227 del CC) o para proceder a su pago al mismo por consignación (art. 2227 inc. $2^{\circ}$ del $C C$ ), de acuerdo con las reglas generales. El depositante puede pedir la restitución aun antes del cumplimiento del plazo y, si no es requerido, no tiene la carga de retirarlos de la empresa depositaria una vez cumplido.

\section{b) El mutuo disenso}

Como el depósito es real, el mutuo disenso no le es aplicable. Si la empresa depositaria y el depositante acuerdan poner fin al contrato, mientras los valores no sean retirados por este de aquella, el contrato subsiste; por lo demás, el depositario no necesita estar justificado por un mutuo disenso previo para retirarlos.

\section{c) La destrucción de los valores}

Como el depósito de valores es irregular, pues recae sobre fungibles (homogéneos) y su titularidad pasa a la depositaria (v. el cap. III) el riesgo de su pérdida es soportado por la depositaria; y lo mismo acaece si la pérdida 
es culpable o dolosa. Por consiguiente, y a diferencia del depósito regular, la destrucción de la cosa depositada no extingue este contrato.

d) Difícilmente cabe pensar en extinciones derivadas de remisión, impropias en el tráfico mercantil, salvo en el interior de una transacción; novaciones, excepto en el mismo caso; compensaciones y confusiones. La resolución por incumplimiento (como si el depositante no paga su remuneración a la depositaria) no extingue el contrato mientras no sea ejecutada la restitución, pero obliga a ejecutarla por consignación.

\section{BiBLIOGRAFÍA}

Baeza Ovalle, Gonzalo (2008). Tratado de derecho comercial. $4^{\mathrm{a}}$ ed. Santiago: LexisNexis.

Castro Boissier, Jaime (1959). El depósito de valores en custodia de un banco. Memoria de licenciatura. Santiago: Universidad Católica de Chile.

Caballero Germain, Guillermo (2013). "La propiedad de los valores custodiados en el Depósito Central de Valores", en Carmen Domínguez Hidalgo y otros (eds.). Estudios de derecho civil, viII: Jornadas Nacionales de Derecho Civil, Santa Cruz, 2012. Santiago: LegalPublishing - Thomson Reuters.

Caballero Germain, Guillermo (2014), "Similitudes y diferencias entre el sistema de anotaciones en cuenta en el registro de accionistas y la representación contable de valores en custodia”, en Eduardo JeQuier Lehuedé. Estudios de derecho comercial. Cuartas Jornadas Chilenas de Derecho Comercial. 5 y 6 de noviembre de 2013. Santiago: LegalPublishing - Thomson Reuters.

Claro Solar, Luis (1932/1992). Explicaciones de derecho civil chileno y comparado. 1932, reimpresión. Santiago: Editorial Jurídica de Chile, 1992, viI, 2.

Claro Solar, Luis (1939/1992). Explicaciones de derecho civil chileno y comparado. 1939, reimpresión. Santiago: Editorial Jurídica de Chile, 1992, XII, 3.

GuZMÁn BRITO, Alejandro (2006). Las cosas incorporales en la doctrina y en el derecho positivo. Santiago: Editorial Jurídica de Chile.

Guzmán Brito, Alejandro (2011a). "La prenda sin desplazamiento de créditos nominativos en el Derecho chileno". Revista Chilena de Derecho Privado, ${ }^{\circ}$ 16. Santiago.

GuZmán Brito, Alejandro (2011b). Tratado de la prenda sin desplazamiento según el derecho chileno. Santiago: Editorial Jurídica de Chile.

GuZMán BRITo, Alejandro (2012). "El contrato de préstamo de valores". Revista de Derecho de la Pontificia Universidad Católica de Valparaíso, 38. $1^{\mathrm{er}}$ semestre. Valparaíso.

GuZmán Brito, Alejandro (2014). "El depósito irregular en el derecho chileno". en Revista Chilena de Derecho Privado "Fernando Fueyo Laneri", No 23. Santiago. 
GuZMán BRito, Alejandro (2015a). "El usufructo de créditos", en Álvaro VIDAL Olivares, Gonzalo Severin Fuster, Claudia Mejías Alonzo (coords.). Estudios de Derecho Civil, X: Jornadas Nacionales de Derecho Civil, Valparaiso, Pontificia Universidad Católica de Valparaíso, 2014. Santiago: Thomson Reuters.

GuZMÁn Brito, Alejandro (2015b). "La naturaleza de los actos y contratos relativos a valores guardados en entidades de depósito y custodia de valores", en Manuel BARRía PAREDES y otros (eds.). Estudios de derecho privado. Homenaje al profesor Ramón Dominguez Aguila. Santiago: Thomson Reuters.

Lara Aguayo, Edinson (2013). Teoría general de los títulos valores en el derecho chileno. Santiago, Abeledo Perrot - Thomson Reuters.

Luna Serrano, Agustín (2013). Las ficciones del derecho. Bogotá: Pontificia Universidad Javeriana.

Mattar Oyarzún, Pablo (1999). Mercado de valores. Sistema de depósito centralizado. Ley $N^{\circ}$ 18.876. Decreto supremo $N^{\circ}$ 734. Santiago: Editorial Jurídica de Chile.

Novoa Galán, Raúl - Gabriela Novoa Muñoz (1997). Derecho del mercado de capitales. $2^{\mathrm{a}}$ ed. Santiago: Editorial jurídica de Chile.

Peñailillo Arévalo, Daniel (2006). Los bienes. La propiedad y otros derechos reales. Santiago: Editorial Jurídica de Chile.

Pomés ANdRAde, Alberto (1966). La mera tenencia. Memoria de licenciatura de la Universidad de Chile. Santiago: Editorial Universitaria.

Puga Vial, Juan (2013). La sociedad anónima y otras sociedades por acciones en el derecho chileno y comparado. Santiago: Editorial Jurídica de Chile, I.

Ramírez Baquero, Adriana, "El depósito de valores en Alemania y el Clearstream Banking AG.”, en Sergio Rodríguez Azuero y otros (eds.) (2006), Temas de derecho financiero contemporáneo. Bogotá: Universidad del Rosario.

Rodríguez Azuero, Sergio (2009). Contratos bancarios. Su significación en América Latina. $6^{\text {a }}$ ed. Bogotá y otras, Legis.

Sandoval LóPez, Ricardo (2015), Derecho comercial, iI: Teoría general de los títulosvalores: Letra de cambio, pagaré, cheque y títulos electrónicos o desincorporados. Santiago: Editorial Jurídica de Chile. 